PONTIFÍCIA UNIVERSIDADE CATÓLICA DO RIO DE JANEIRO

\title{
As Percepções do Consumidor de eSports Brasileiro sobre os Patrocinadores
}

\section{Lucas de Souza Matos}

Trabalho de Conclusão de Curso

Centro de CIÊNCIAS SOCIAIS - CCS

DePARTAMENTO de AdMINISTRAÇÃO

Graduação em Administração de Empresas 
Lucas de Souza Matos

\section{As Percepções do Consumidor de eSports Brasileiro sobre os Patrocinadores}

\section{Trabalho de Conclusão de Curso}

Trabalho de Conclusão de Curso, apresentado ao programa de graduação em Administração da PUC-Rio como requisito parcial para a obtenção do título de graduação em Administração.

Orientador: Jorge Brantes Ferreira

Rio de Janeiro novembro de 2021. 


\section{AGRADECIMENTOS}

Deixo aqui meus agradecimentos para as pessoas que me apoiaram e acompanharam ao longo da minha caminhada acadêmica.

Primeiramente, aos meus pais, Flávio e Carla, por todo o amor e carinho nesses vinte e seis anos de vida. $\mathrm{O}$ apoio incondicional e a fé de vocês em mim foi, é e continuará sendo essencial para meu sucesso e felicidade.

Ao restante da minha família, agradeço por todo o amor, companhia e palavras inspiradoras. Aqui agradeço especialmente à minha tia Fátima e meu tio Sydney, que sempre acompanharam meu desenvolvimento acadêmico e profissional, ajudando sempre que possível.

Agradeço imensamente ao professor Jorge Brantes Ferreira, meu orientador, cuja disponibilidade ímpar, experiência e conhecimentos foram cruciais para a realização deste trabalho.

Agradeço especialmente ao Ailton Soares Sousa, por sua compreensão neste momento difícil e acreditar no meu potencial.

Agradeço também aos meus amigos mais próximos, Hércules, Lucas Milioni, Taian e Yan, pelos últimos dez anos de companheirismo e pelos muitos anos que seguirão. A presença de vocês tornou minha vida sempre mais leve e alegre.

Por fim, agradeço a Luiza Leite. Por todo seu amor, companheirismo e paciência. Pelos dias de lazer e pelos dias de labuta. Sem você esse trabalho não poderia ter sido realizado. 


\section{RESUMO}

Este estudo pretende avaliar as percepções do público consumidor de eSports brasileiro sobre os patrocinadores atuantes neste setor, buscando avançar a exploração da indústria de eSports na academia, produzindo insights relevantes para as empresas atuantes no setor e pesquisadores da área. Para este fim, é usado o modelo concebido por Huettermann et al. (2020), identificado por meio da revisão de literatura sobre o tema de patrocínios na indústria de eSports. São verificadas as hipóteses propostas pelos autores quando aplicadas ao contexto brasileiro, de modo a testar a validade do modelo e detectar possíveis diferenças de percepções e motivações no público brasileiro, bem como diferenças nos efeitos verificados entre os construtos do modelo. O modelo é testado por meio de uma survey em uma amostra de 202 brasileiros consumidores regulares de eSports. Os dados obtidos, analisados por meio de modelagem de equações estruturais, confirmam a maior parte das hipóteses formuladas e apresentam as relações entre os construtos quando aplicados à amostra brasileira. Os resultados desta pesquisa sugerem que empresas que realizarem patrocínios efetivos no meio de eSports podem se beneficiar de melhorias na percepção de boa vontade, atitude do público-alvo e intenção de compra. São analisadas as diferenças entre os achados deste trabalho e os achados de Huettermann et al. (2020) e propostas razões para explicá-las.

\section{PALAVRAS CHAVES}

eSports; patrocínio; marketing; administração esportiva; consumidores; espectadores; percepção. 


\section{ABSTRACT}

The purpose of this study is to evaluate Brazilian esports consumer's perceptions of the acting sponsors in the eSports market. It aims to advance the academic understanding of the eSports industry and generate relevant insights for companies and researchers in the segment. To this end, the conceptual model proposed by Huettermann et al. (2020) is used. This model was identified by reviewing the academic literature regarding eSports sponsorship. The proposed hypotheses are verified in the context of the Brazilian eSports market, with the aim of testing the conceptual model's validity and detect possible differences in consumer's perceptions and effects between the model's constructs. The model is tested with a cross-sectional survey, resulting in a sample of 202 Brazilian regular eSports consumers. The resulting data is then analyzed through structural equation modeling, confirming most of the proposed hypotheses and revealing the relationship between constructs when applied to the Brazilian sample. This study's results suggests that companies sponsoring entities within the Brazilian eSports market can enjoy improvements in consumer's perceptions of goodwill, attitude regarding the sponsor and intention to buy the sponsor's products. The differences between this study's results and those recorded by Huettermann et al. (2020) are analyzed, and hypotheses are proposed to explain them.

\section{KEY WORDS}

eSports; sponsorship; marketing; sports management; consumers; spectators; perceptions. 


\section{SUMÁRIO}

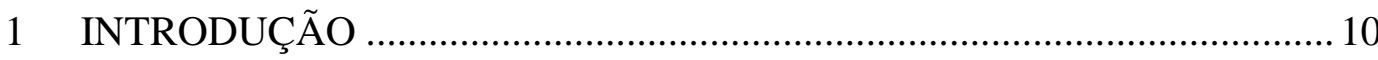

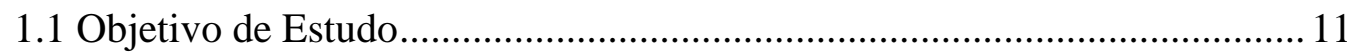

1.2 Relevância do Estudo................................................................................ 11

1.3 Questões a investigar ............................................................................... 12

1.4 Delimitação do Estudo ................................................................................ 13

1.5 Organização do Estudo …………………………………………………..... 13

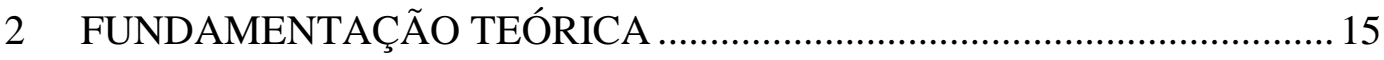

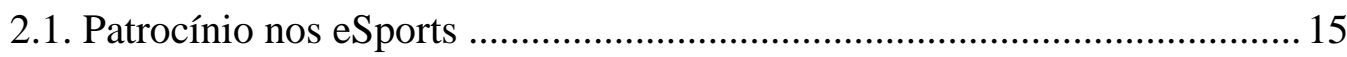

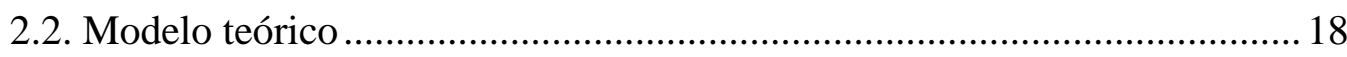

2.3. Motivação e consumo de eSports ................................................................... 19

2.4. Atitude de marca de eSports ....................................................................2 23

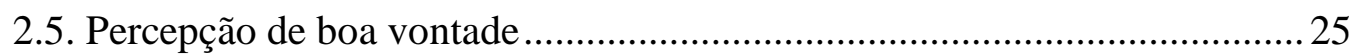

2.6. Atitude em relação ao patrocinador ...............................................................26

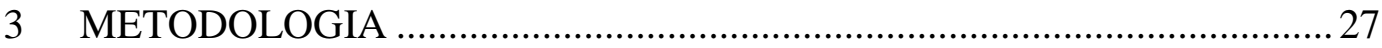

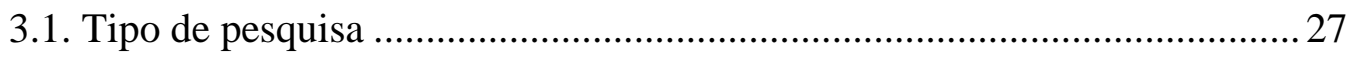

3.2. Operacionalização das variáveis ..................................................................2 27

3.2.1. Definição operacional das variáveis.....................................................2

3.2.2. Procedimentos de tradução e adaptação das escalas utilizadas............. 30

3.2.3. Pré-teste do instrumento de pesquisa ...................................................... 30

3.3. População e amostra …………………………………………………….... 31

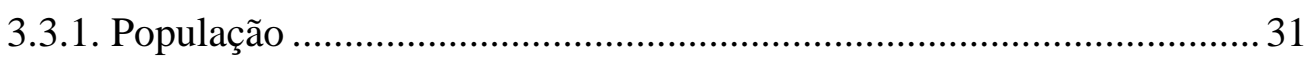

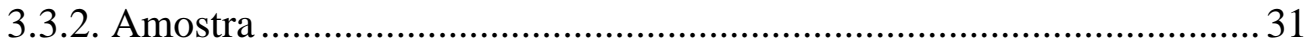

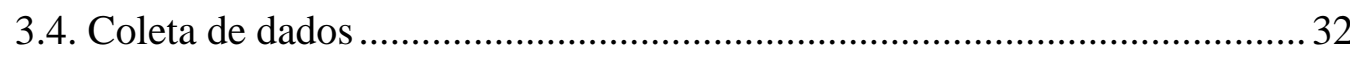

3.4.1. O instrumento de coleta de dados ....................................................... 32

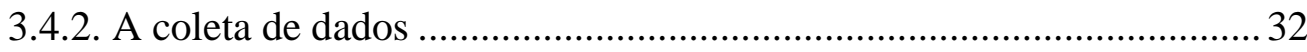




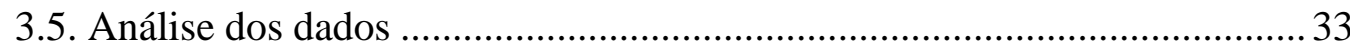

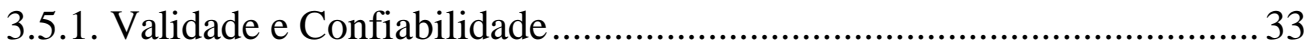

3.5.2. Análises Estatísticas ............................................................................ 34

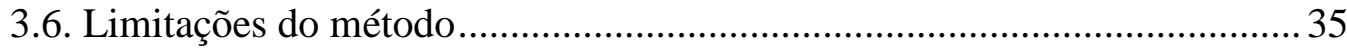

3.6.1. Limitações relacionadas ao critério de amostragem .............................35

3.6.2. Limitações decorrentes da coleta de dados ......................................... 35

4 MODELAGEM E ANÁLISE DOS DADOS ................................................ 37

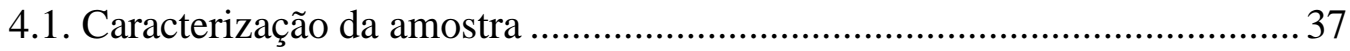

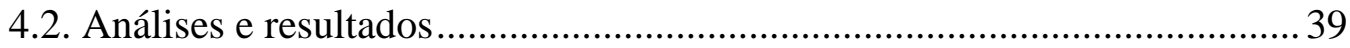

4.2.1. Avaliação do Modelo de Mensuração .................................................... 39

4.2.2. Validade e Confiabilidade dos Construtos ............................................. 40

4.2.3. Teste das Hipóteses de Pesquisa ......................................................... 44

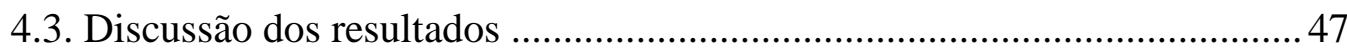

4.3.1. Influência dos Motivos para Assistir eSports na Atitude de Marca de

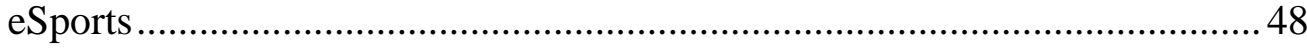

4.3.2. Influência da Atitude de Marca de eSports e da Percepção de Boa Vontade na Atitude em Relação ao Patrocinador............................................. 49

4.3.3. Influência da Atitude de Marca de eSports e da Atitude em Relação ao Patrocinador Na Intenção de Compra de Produto do Patrocinador ............... 51

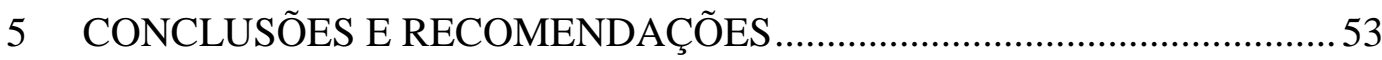

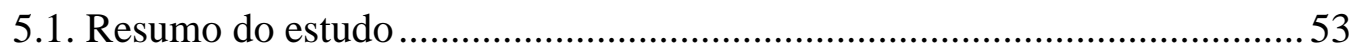

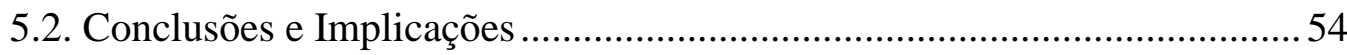

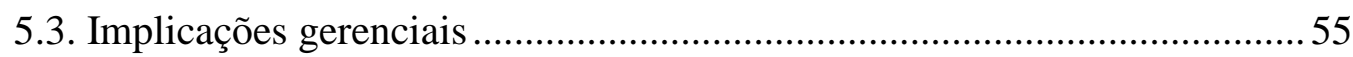

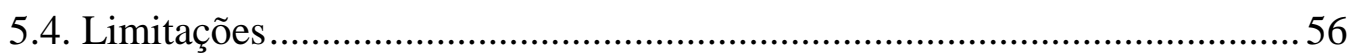

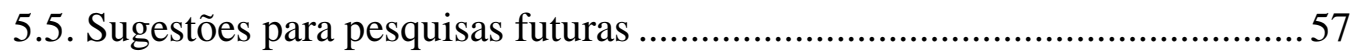

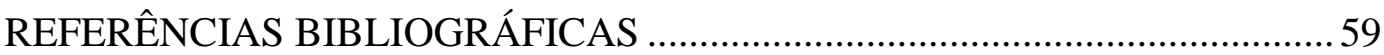

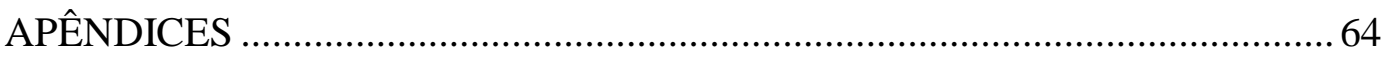

Apêndice A - Questionário utilizado na pesquisa............................................. 64 


\section{LISTA DE FIGURAS}

Figura 2.1: Modelo Conceitual (HUETTERMANN et al., 2020) ......................... 19

Figura 2.2: Escala de Motivação para Consumo de Esportes, EMCE .................. 20

Figura 4.1: Coeficientes Padronizados Estimados e proporção da variância explicada das variáveis dependentes para o modelo de Huettermann et al. (2020) 


\section{LISTA DE QUADROS}

Quadro 4.1: Matriz de Correlação entre Construtos .............................................. 41

Quadro 4.2: Matriz de Validade Discriminante...................................................... 43 


\section{LISTA DE TABELAS}

Tabela 3.1: Escalas e medidas operacionais para cada variável do instrumento de

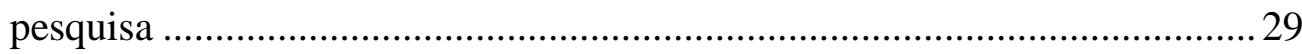

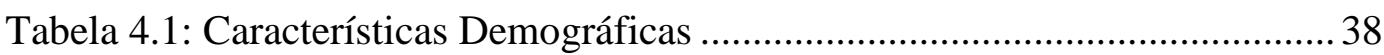

Tabela 4.2: Índices de Ajuste (Fit) do Modelo de Mensuração............................. 39

Tabela 4.3- Confiabilidade, Confiabilidade Composta e Variância Extraída Média

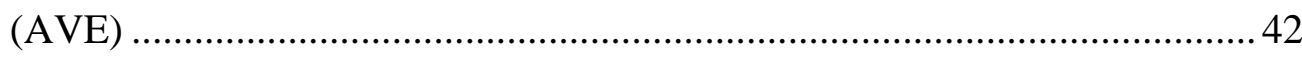

Tabela 4.4: Coeficientes Padronizados Estimados, Hipóteses e Significâncias.... 44

Tabela 4.5: Resumo dos Resultados dos Testes de Hipóteses............................... 47 


\section{INTRODUÇÃO}

Os eSports podem ser definidos como competições de jogos eletrônicos à nível profissional e em formatos organizados, como campeonatos e ligas (NEWZOO, 2021). Estas competições contam com objetivos específicos, como títulos de campeonatos e prêmios em dinheiro, e exibem distinções claras entre os jogadores e times que competem entre si.

Nos últimos anos, a popularidade desta modalidade esportiva vem aumentando vertiginosamente, trazendo luz ao potencial econômico envolvido na indústria. Em 2020, a indústria global de eSports rendeu em torno de \$1.1 bilhão de dólares, atraindo cerca de 495 milhões de espectadores (MA et al., 2021). Projeções estimam que a indústria renderá quase \$3 bilhões de dólares em 2022 (HUETTERMAN et al., 2020). O público de eSports já supera em número as audiências de esportes tradicionais como o futebol americano e o rugby (AYLES, 2019). Além disso, é composto por um demográfico jovem e lucrativo, que está se tornando cada vez mais desconectado de plataformas de mídia convencionais, o que dificulta o acesso de patrocinadores (HUETTERMANN et al., 2020). Esse é um fator crítico, visto que patrocínios atualmente constituem a maior fonte de renda na indústria de eSports, representando mais de $40 \%$ da renda do setor (NIELSEN SPORTS, 2019).

Estes fatos estão levando muitas marcas e times tradicionalmente atuantes do setor de esportes convencionais a buscarem entrada na indústria de eSports. Equipes esportivas internacionais como AS Roma, Los Angeles Lakers, New York Yankees e Paris Saint-Germain, são apenas alguns dos novos entrantes neste cenário (HERSHEY, 2020). No Brasil este cenário é refletido por organizações esportivas tradicionais, como o Flamengo e Cruzeiro, e por times patrocinados por grandes empresas do comercio digital, como KaBuM! e-Sports e a RED Canids Kalunga (REIS, 2020). Por sinal, o Brasil, que já é o maior consumidor de games da América Latina e $13^{\circ}$ em consumo mundial (AGÊNCIA BRASIL, 2019), apresenta números promissores em sua cena de eSports. Dentre os mais de 400 milhões de espectadores de eSports em 2019, mais de 21 milhões eram brasileiros. É a terceira maior audiência do mundo, atrás apenas da China e dos Estados Unidos, segundo Chiminazzo \& Marques (2020). 
Tamanha audiência e engajamento sugerem que o mercado brasileiro de eSports possui grande potencial para ativações de patrocínios. Entretanto, há uma escassez de literatura específica sobre a indústria de eSports no Brasil, especialmente no que diz respeito às motivações do público. A compreensão dos fatores que motivam as percepções do público gamer brasileiro em relação aos patrocinadores é interessante tanto para empresas, quanto para os pesquisadores do comportamento do consumidor brasileiro.

\subsection{Objetivo de Estudo}

Este estudo pretende avaliar se empresas que adentrarem a indústria de eSports brasileira por meio de patrocínios se beneficiarão de percepções positivas por parte dos consumidores, como: maior intenção de compra, percepção de boa vontade e atitude do público em sua relação.

O modelo utilizado é baseado majoritariamente no desenvolvido por Huettermann et al. (2020) em seu estudo: "Esports Sponsorship: An Empirical Examination of Esports Consumers' Perceptions of Non-Endemic Sponsors". Assim sendo, este estudo pretende aplicar o modelo concebido pelos autores ao contexto de eSports brasileiro, com o intuito de descobrir se existem diferenças significativas entre os resultados obtidos pelos autores em uma amostragem suíça, aos resultados obtidos com uma amostragem brasileira.

Este estudo pretende também corroborar para a validade acadêmica do modelo de Huettermann et al. (2020), adaptado do modelo de Biscaia et al. (2017), e para as escalas de Trail \& James (2001) e Dees et al. (2008).

\subsection{Relevância do Estudo}

Embora exista literatura prévia sobre patrocínios esportivos que busque compreender as percepções do público consumidor sobre os patrocinadores e o impacto destas sobre a intenção de compra de produtos dos patrocinadores (BISCAIA et al., 2017; DEES et al., 2008; TRAIL; JAMES, 2001), são poucas as que efetivamente realizam essa investigação no contexto de eSports (ELASRI- 
EJJABERI et al., 2020; HUETTERMAN et al., 2020; ROGERS et al., 2020). Destes poucos estudos focados em eSports, todos foram realizados com amostras nativas de países europeus como Suíça (HUETTERMAN et al., 2020) e Espanha (ELASRI-EJJABERI et al., 2020).

Este trabalho pretende contribuir na exploração do emergente cenário dos eSports no meio acadêmico corroborando o estudo de Huettermann et al. (2020). Para este fim, foram estudadas as percepções dos consumidores de eSports sobre os patrocinadores no setor e os construtos relacionados a elas, como: atitude em relação ao patrocinador, percepção de boa vontade e intenção de compra de produtos do patrocinador.

Desta forma, são produzidos insights relevantes para companhias que estejam buscando oportunidades de capitalização na indústria brasileira de eSports.

\subsection{Questões a investigar}

Neste presente estudo serão investigadas as validades do modelo e das hipóteses de Huettermann et al. (2020), quando aplicadas ao contexto de eSports brasileiro. Busca-se entender se o patrocínio na indústria de eSports no Brasil trará os mesmos benefícios verificados em estudos anteriores. Assim, a principal questão desta pesquisa é:

1) Patrocinadores no mercado de eSports brasileiro se beneficiarão de ganhos em atitude de marca, percepção de boa vontade e intenção de compra de seus produtos como foi verificado no estudo de Huettermann et al. (2020)?

A segunda questão refere-se à análise dos motivos pelos quais os resultados deste estudo diferem do estudo original. Sendo assim a segunda questão a investigar é:

2) Quais fatores presentes no público consumidor de eSports brasileiro justificam as divergências observadas nos resultados deste estudo em relação ao estudo original? 


\subsection{Delimitação do Estudo}

Este estudo busca estudar somente as percepções dos consumidores regulares de eSports brasileiros. Esta delimitação é garantida pela inclusão de duas questões de validação no instrumento de pesquisa que buscam checar se o respondente assiste ou não eSports e com qual frequência este o faz, considerando somente respostas em que o participante se diz um espectador frequente. $\mathrm{O}$ instrumento de pesquisa foi divulgado somente para brasileiros e em grupos ou comunidades nacionais nas redes sociais disponíveis. A coleta de dados ocorreu entre setembro e outubro de 2021.

\subsection{Organização do Estudo}

Este trabalho está organizado da seguinte forma:

O primeiro capítulo apresenta os objetivos da pesquisa e discute sua inserção teórica, ressaltando sua relevância para a pesquisa sobre comportamento do consumidor de eSports e patrocínio no setor, além das questões a serem investigadas e das delimitações do estudo.

O segundo capítulo descreve a revisão de literatura realizada sobre os temas de patrocínio esportivo e no setor de eSports, com um foco particular nos modelos, construtos e escalas que foram utilizados ao longo dos anos para a compreensão das variáveis motivacionais e comportamentais que determinam a efetividade de patrocínios sob a perspectiva do público-alvo. Esta etapa termina com a apresentação do modelo utilizado por este trabalho e a enunciação das hipóteses da pesquisa.

O terceiro capítulo detalha a metodologia empregada neste trabalho, definindo o tipo de pesquisa realizado, a população de interesse, o método de amostragem, os procedimentos para a elaboração do instrumento de pesquisa, a forma de coleta de dados, os métodos empregados na análise dos dados e, por fim, as limitações do estudo.

O capítulo quatro apresenta os resultados do estudo. É realizado o teste do modelo de mensuração adotado e do modelo estrutural considerado, além de 
serem verificadas as hipóteses da pesquisa e discutidas as relações encontradas entre os construtos estudados.

O capítulo cinco conclui o trabalho, resumindo o estudo e apresentando suas principais conclusões e contribuições. São avaliadas também as limitações do estudo e feitas sugestões para novas pesquisas. 


\section{FUNDAMENTAÇÃO TEÓRICA}

\subsection{Patrocínio nos eSports}

Este trabalho se baseia majoritariamente no artigo de Huettermann et al. (2020), Esports Sponsorship: An Empirical Examination of Esports Consumers' Perceptions of Non-Endemic Sponsors, buscando adaptá-lo para o contexto do mercado de eSports brasileiro. No artigo original, os autores buscam avaliar as percepções dos consumidores de eSports quanto aos patrocinadores não endêmicos. Para este fim, utilizam uma adaptação do bem estabelecido modelo de patrocínio esportivo de Biscaia et al. (2017).

Na literatura não parece haver um consenso quanto à definição acadêmica de patrocínio. As definições evoluíram e se tornaram mais amplas ao longo do tempo, como pode-se observar nas definições de Meenaghan (1983, p.9, tradução minha): “(...) pode ser considerado como a provisão de assistência, financeira ou em espécie, para uma atividade por uma organização comercial, de forma a atingir objetivos comerciais." e Mullin et al. (2000, apud NICKELL et al., 2011, p.578, tradução minha): “(...) é a aquisição dos direitos de afiliação ou associação direta com um produto, pessoa, organização, time, liga ou evento, com o propósito de derivar benefícios desta afiliação ou associação".

A evolução da literatura sugere que, ao longo do tempo, as definições tratam o patrocínio menos como uma troca financeira, com resultado comercial previsível, e mais num sentido abrangente, passando a entender que existem benefícios intangíveis na associação às empresas.

Brochand et al. (1999 apud FERNANDES, 2009) oferecem uma definição mais detalhada de patrocínio: é um componente da comunicação que permite a divulgação do nome e imagem de uma empresa e de seus produtos, associando-se a um determinado evento, ação ou a uma entidade esportiva ou cultural. Para os autores, o patrocínio pode ser dividido entre duas vertentes, separadas pelos objetivos a serem alcançados: o patrocínio institucional e o patrocínio promocional. 
No patrocínio institucional, o objetivo é a valorização da imagem e o aumento da notoriedade da empresa. Este pode ser usado como veículo de comunicação externa, divulgando a imagem da empresa, ou interna, contribuindo para a cultura organizacional. Já no patrocínio promocional, o objetivo é promover a marca e seus produtos associando-os a eventos ou entidades culturais e esportivas. Nesta vertente, a promoção da marca acontece pelo contato direto com o público-alvo dos produtos ou marcas envolvidos no patrocínio (BROCHAND et al., 1999 apud FERNANDES, 2009).

Já Huettermann et al. (2020), adotam em seu texto o conceito de Nickell et al. (2011) para patrocínios: é uma troca entre duas partes onde ambas se beneficiam de sua contínua associação. Esta é a definição que será adotada para este trabalho.

Acadêmicos da administração esportiva concordam que o processo pelo qual consumidores de eSports percebem e interpretam toda a gama de estímulos provindos dos eSports pode trazer à tona emoções e influenciar suas percepções (HALLMANN; GIEL, 2017). Entre esses estímulos, estão as mensagens de patrocinadores não endêmicos que buscam alcançar sua audiência jovem (HUETTERMANN et al., 2020).

No que diz respeito às marcas patrocinadoras, pode-se distinguir dois tipos: endêmicas e não endêmicas. $\mathrm{O}$ patrocinador endêmico é aquele cujo produto ou serviço está diretamente ligado às atividades do patrocinado ou de seu público-alvo. No contexto dos eSports, estas seriam marcas de videogames, hardware, software, periféricos e provedores de internet, entre outros. Alguns exemplos deste tipo de patrocinador seriam a Intel, a Comcast Xfinity, a Dell e a Cisco. Já o patrocinador não endêmico é aquele que não tem conexões tão claras com o patrocinado ou seu público-alvo (ELASRI-EJJABERI et al., 2020). Alguns dos maiores patrocinadores de eSports da atualidade pertencem a essa categoria, como: a gigante Red Bull e a Mountain Dew, ambas patrocinadoras de ligas de eSports (ESL GAMING, 2018; RED BULL, 2021). Também temos a BMW, que patrocina atualmente cinco grandes times do cenário internacional de eSports: Cloud 9, Fnatic, FunPlus Phoenix, G2Esports e T1 Entertainment (HITT, 2020); por último, tem-se a Gillette no cenário brasileiro, que patrocina não só o CBLOL 
- Campeonato Brasileiro de League of Legends - quanto o jogador Gabriel "Kami" Bohm, um dos nomes mais conhecidos e queridos do cenário brasileiro de League of Legends (ABC DA COMUNICAÇÃO, 2020).

Entretanto, existem desafios para patrocinadores que almejam entrar no cenário de eSports. Como uma indústria em desenvolvimento, é vulnerável a uma gama de riscos que podem afetar negativamente seu ecossistema e seus stakeholders (FREITAS et al., 2020). A indústria já sofreu diversas vezes com incidentes de comportamento antiético e corrupção no passado (SHABIR, 2017), com exemplos de comportamento tóxico, sexismo, apostas ilegais, cheating, cyber ataques e doping (STRÖH, 2017). Essas ocorrências continuam aparecendo esporadicamente no cenário, como é o caso do recente escândalo envolvendo a gigante americana Blizzard, desenvolvedora de três dos mais consagrados eSports recentes, Hearthstone, Overwatch e Starcraft. Após ser processada publicamente pelo Department of Fair Employment and Housing da California, foi constatado um histórico de abusos morais e sexuais, discriminação, sexismo e retaliação de longa data (FENLON, 2021). Como existe uma grande chance de a imagem do patrocinador ser associada com o patrocinado, as empresas devem adentrar este mercado de maneira meticulosa e, acima de tudo, cuidadosa (STRÖH, 2017).

Outro fator de destaque é que, embora já tenha sido provado que os espectadores de eSports entendem a necessidade econômica de patrocinadores (STRÖH, 2017), eles se mostram hostis a patrocinadores visto como não autênticos ou oportunistas (ROGERS et al., 2020). Huettermann et al. (2020) citam como exemplo de um caso falho, o patrocínio da Mercedes-Benz da ESL One, um campeonato global de eSports. Neste, um narrador constatou que a performance notável dos atletas só não era tão notável quanto a performance do Sedan E-Class Mercedes-Benz. A recepção da jogada de marketing foi vergonhosa, causando indignação e vergonha ao público do evento, que rapidamente foi às redes sociais, gerando "memes"1 para ridicularizar publicamente a empresa. Esse panorama dificulta a entrada de patrocinadores não

\footnotetext{
${ }^{1} \mathrm{O}$ termo é usado para descrever o conceito de qualquer vídeo, imagem, frase, ideia, música etc., relacionados ao humor, que se espalha entre vários usuários na internet, tornando-se, normalmente, viral.
} 
endêmicos, cuja atuação pode ser interpretada como oportunista ou de mal gosto, tornando-se prejudicial à marca.

\subsection{Modelo teórico}

O modelo conceitual usado neste trabalho foi desenvolvido por Biscaia et al. (2017) e adaptado por Huettermann et al. (2020) para o contexto de eSports. O original tem o propósito de examinar o impacto da marca de uma equipe esportiva na imagem da marca do seu patrocinador. Já Biscaia et al. (2017) avaliam os efeitos diretos e indiretos tanto das variáveis relacionadas à equipe esportiva quanto das variáveis relacionadas ao patrocinador, em relação à intenção de compra de produtos do patrocinador. Sua proposta é de que o consumo anterior, a lealdade atitudinal prévia e a motivação para consumo, relacionados à uma equipe esportiva (através da compra de mercadorias e ingressos para jogos), impactariam a satisfação geral com a equipe e a lealdade pós-temporadas/pós campeonatos para com a mesma. Assim, tais fatores de experiências do consumidor com a marca da equipe impactariam, direta ou indiretamente, fatores de experiência de marca do patrocinador. Dentre estes fatores estariam: "familiaridade da marca, fit entre equipe/patrocinador, percepção de exclusividade ou ubiquidade do patrocinador, percepção de boa vontade do patrocinador, atitude em relação ao patrocinador e no fim e intenção de compra de produto do patrocinador" (HUETTERMANN et al., 2020, p.4, tradução minha).

O modelo de Biscaia et al. (2017) nos parece adequado para este estudo, como feito por Huettermann et al. (2020), pois provê uma base de avaliação das percepções dos consumidores de eSports sobre patrocinadores não endêmicos. Já que, o modelo de Biscaia et al. (2017) apresenta uma estrutura para examinar como consumidores enxergam os patrocinadores, através de suas experiências com uma equipe esportiva convencional e suas experiências com a marca do patrocinador. No entanto, devido à complexidade do modelo original de Biscaia et al. (2017) e da mudança de contexto de esportes convencionais para eSports, Huettermann et al. (2020) focaram apenas em uma fração do modelo. Foram considerados dois aspectos da experiência relacionada a equipes esportivas são eles: 1. motivos para consumo de eSports e 2. a atitude de marca sobre eSports; e três aspectos da experiência de marca relacionada ao patrocinador: 1. a percepção 
de boa vontade do patrocinador, 2. a atitude em relação ao patrocinador e, por último, 3. a intenção de compra de produto do patrocinador.

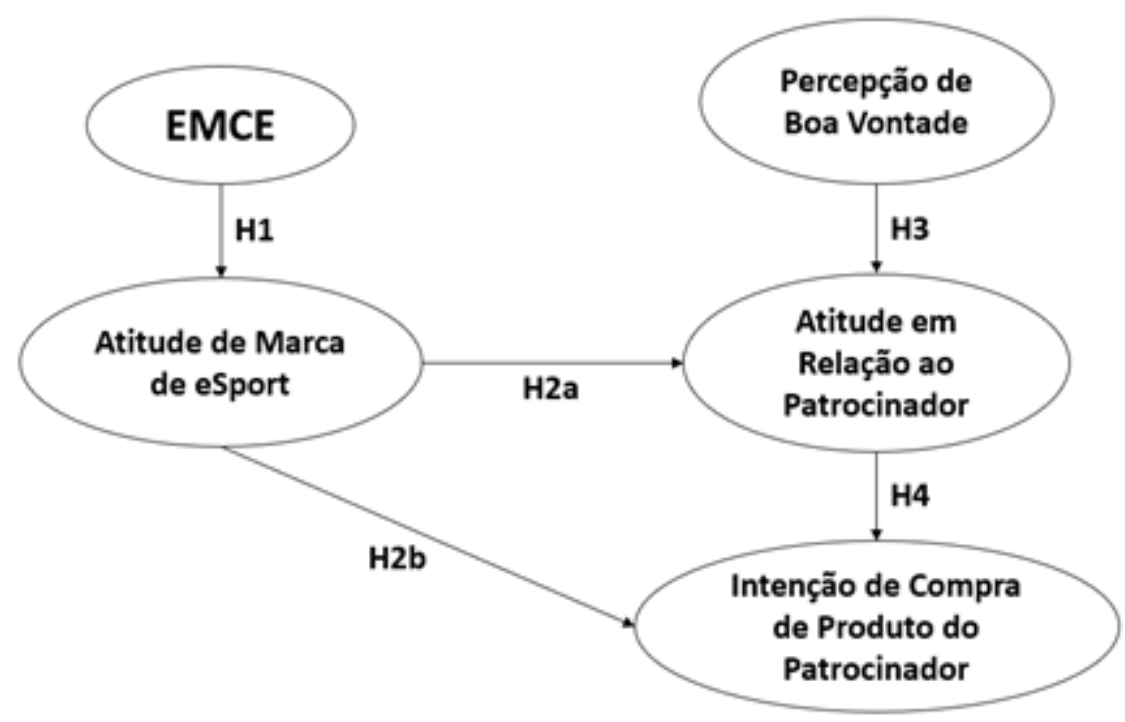

Figura 2.1: Modelo Conceitual (HUETTERMANN et al., 2020)

Em essência, neste estudo o modelo de Biscaia et al. (2017) adaptado por Huettermann et al. (2020) é usado para examinar as relações entre as motivações de consumo de eSports e a atitude de marca sobre eSports dos consumidores de eSports e suas percepções sobre patrocinadores não endêmicos no cenário de eSports no Brasil, com o objetivo de determinar a efetividade de patrocínios não endêmicos nos eSports. A Figura 1 ilustra os construtos e hipóteses propostas por Huettermann et al. (2020) com base no modelo original. Adiante, cada construto será explorado, assim como os relacionamentos entre eles.

\subsection{Motivação e consumo de eSports}

Motivação é uma força psicológica, responsável pela iniciação, persistência e direcionamento de comportamentos orientados por objetivos. Inclui fatores biológicos como fome, sede e autopreservação e fatores sociais como a necessidade de autorrealização e afiliação (COLMAN, 2009). Motivação diferencia-se de motivo, visto que ela é um processo psicológico que influencia comportamentos, enquanto motivos são a razão pela qual adota-se um 
comportamento específico (DECI; RYAN, 2000), entre eles a prática e consumo de eSports.

Segundo Robinson \& Trail (2005), a motivação é um dos construtos mais utilizados em trabalhos que buscam prever ou avaliar o comportamento do consumidor de eSports. Huettermann et al. (2020) usaram a Escala de Motivação para Consumo de Esportes ou EMCE de Trail \& James (2001), uma das mais difundidas escalas de motivação, para avaliar a motivação do consumidor de eSports.

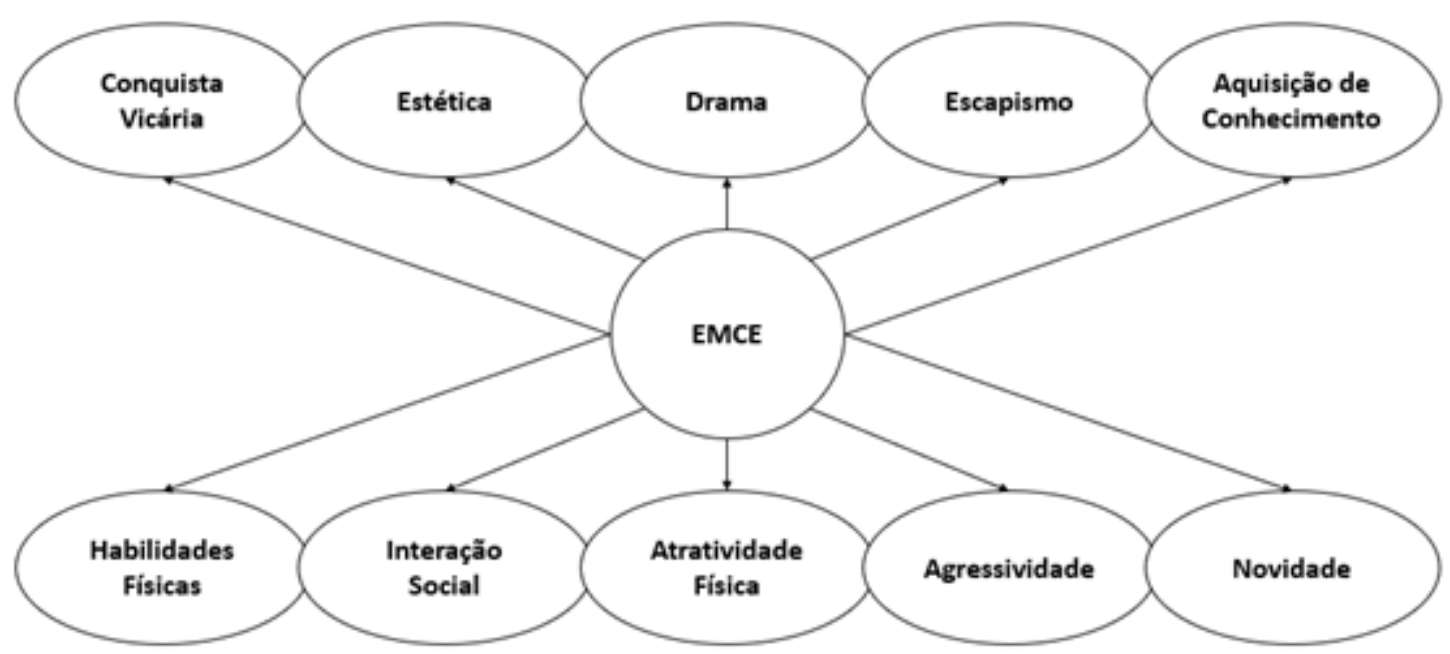

Figura 2.2: Escala de Motivação para Consumo de Esportes, EMCE

A EMCE é composta por dez motivos que influenciam o consumo de esportes: conquista vicária, estética, drama, escapismo, aquisição de conhecimento, habilidades físicas, interação social, atratividade física, agressividade e novidade. Na figura 2 estão expostos os motivos que formam a EMCE. A conquista vicária pode ser definida como a necessidade de ser associado a entidades percebidas como bem-sucedidas (HUETTERMANN et al., 2020). Essa necessidade é saciada por associação de forma vicária, pela conexão de um torcedor a uma equipe ou jogador de sucesso (LEE et al., 2009). O aumento do sentimento de conquista vicária, neste caso, traria um aumento também das atitudes positivas de marcas de eSports.

Estética, enquanto motivo, diz respeito à beleza e valor artístico inerente ao esporte ou jogo. (TRAIL et al., 2000). No caso dos eSports, um jogo com 
efeitos gráficos bem desenvolvidos e executados e eventos de eSports visualmente impressionantes podem criar experiências esteticamente atraentes. Espectadores expostos a esses efeitos visuais podem sentir satisfação por conta do valor estético deles. Logo, um aumento das qualidades estéticas relacionadas ao consumo de eSports poderia aumentar também as atitudes positivas de marcas de eSports.

Drama como motivação para o consumo de eSports, por sua vez, provém do prazer da incerteza e suspense envolvidos em partidas de esportes ou eSports (XIAO, 2019). Fink et al. (2002) corroboram essa definição, afirmando que drama é a necessidade de stress prazeroso ou estimulante que provém do suspense nos eventos. Assim, maior estimulação e suspense por meio do drama devem trazer aumentos às atitudes positivas de marcas de eSports.

Já o escapismo é a fuga realizada por indivíduo frente seu estresse, problemas e atividades entediantes em seu cotidiano (XIAO, 2019). Weiss \& Schiele (2013) e Hamari \& Sjöblom (2017) concluíram que escapismo é um motivo e preditor do consumo de eSports. Quanto maior o escape que um indivíduo conseguir derivar do consumo de eSports, maiores devem ser suas atitudes positivas de marcas de eSports.

Para Fink et al. (2002), a aquisição de conhecimento como motivo provém da necessidade de se aprender ou aprofundar sobre uma equipe ou jogador, por meio da interação e consumo de mídia esportiva. Enquanto no contexto de eSports, essa definição torna-se incompleta. Ao assistir eSports, espectadores podem aprender técnicas e estratégias que, por sua vez, podem ser implementadas em sua própria experiência de jogo. Assim, a aquisição de conhecimento pode ser um motivo para consumo de eSports.

Habilidades físicas são vistas como um motivo para consumo de eSports por se relacionarem com a apreciação das habilidades físicas dos atletas ou a performance da equipe (FINK et al., 2002). Nos eSports, essa performance se traduz no que se conhece por habilidades mecânicas, um conjunto de coordenação motora, reflexos e agilidade que permite com que jogadores se destaquem individualmente. Quando se trata de eSports, a apreciação do consumidor pelas habilidades dos jogadores se traduz em sua apreciação pelo evento (PIZZO et al., 2018) e, teoricamente, na atitude de marcas de eSports. 
Interação social é a necessidade não só de interagir com outros, mas de sentir-se parte de um grupo social (TRAIL et al., 2000). O consumo de esportes e eSports também pode ser considerado uma atividade social por servir como tópico de conversação, ajudando indivíduos a formarem laços entre si (GANTZ; WENNER, 1995). As atitudes de marcas de eSports positivas devem crescer ao passo que os consumidores se sentem mais incluídos na comunidade gamer.

A atratividade física dos atletas é, segundo Fink et al. (2002), o sex appeal de um atleta ou de um grupo de atletas. Aqui trata-se das percepções dos consumidores sobre os jogadores em si, isto é, sua aparência física. Teoricamente, quanto mais atraentes os jogadores forem para o público consumidor, mais positivas seriam suas atitudes de marcas de eSports. Entretanto, nota-se que o foco dos eSports, salvo exceções, é no game que é jogado, não no atleta (XIAO, 2019). Isso pode ser observado nas próprias transmissões de eSports, onde só ocasionalmente são vistos os rostos dos atletas, geralmente no canto da tela de modo a não interferir no foco central, que é o jogo.

A agressão foi adicionada como motivo à EMCE por Lee et al. (2009). Segundo os mesmos autores, o comportamento agressivo de intimidação, tensão e até mesmo brigas, seria apreciado pelos consumidores de esportes. Dada a popularidade de esportes de combate - à exemplo dos campeonatos de artes marciais mistas (MMA) como o UFC - parece de fato haver uma demanda por agressividade e violência como entretenimento por parte dos consumidores de esportes. Trazendo para o contexto dos eSports, a percepção de atitudes ou jogadas agressivas nas partidas provavelmente impacta as atitudes de marcas de eSports positivamente.

Novidade foi incluída na EMCE por James et al. (2002), que a definiu como a oportunidade de assistir a uma nova equipe em um novo local. Os autores provaram que este senso de novidade impacta positivamente na venda de ingressos para os eventos esportivos. Extrapolando para o contexto de eSports, pode-se inferir que a novidade de assistir novos times no cenário levaria a atitudes de marcas de eSports mais positivas.

Todas as motivações citadas anteriormente foram ligadas a uma gama de desfechos psicológicos e comportamentais positivos, como atitude de marca, 
frequência de consumo e intenção de compra (HUETTERMANN et al., 2020). Na atual literatura que pesquisa os motivos de consumo dos espectadores de eSports, diversos autores como Pizzo et al. (2018) e Qian et al. (2020) concluíram que os motivos para consumo observados no público de eSports e esportes tradicionais são similares, tanto no meio digital quanto físico. Estes achados corroboram a hipótese de que os motivos que compõem a EMCE também explicam o comportamento dos consumidores de eSports. Com base nessa similaridade dos motivos de consumo, Huettermann et al. (2020) propuseram que os mesmos podem ser extrapolados para a atitude de marca de eSports, desenvolvendo a primeira hipótese:

Hipótese 1: Os motivos para consumo de eSports impactarão positivamente a atitude de marca de eSports

\subsection{Atitude de marca de eSports}

De forma geral, a literatura da psicologia do consumo, seguindo as formulações de Fishbein e Ajzen (1975), entende atitude como uma maneira de “expectancy-value" (PERCEY; ROSSITER, 1992, p. 266), ou seja, a ideia geral é que existem expectativas, bem como valores ou crenças que afetam o comportamento-resposta de maneira consistentemente favorável ou desfavorável a um dado objeto. Assim, as atitudes são desenvolvidas e modificadas com base em avaliações de crenças e valores. Em suma, para Huettermann et al. (2020), atitude de marca (brand attitude) é, simplesmente, constituída pelos julgamentos e pela avaliação geral que o consumidor faz da marca.

Com o objetivo de aumentar o reconhecimento de marca (brand awareness) e a imagem (brand image), a escolha do patrocínio, como uma ferramenta de marketing, se torna uma estratégia valiosa para as empresas. Segundo Huettermann et al. (2020), estudos anteriores de patrocínio em esportes convencionais mostraram que "atividades de patrocínio podem impactar positivamente na atitude do consumidor em relação ao patrocinador e aumentar a venda de produtos" (p.8). No entanto, para isso, no contexto de patrocínio, é primordial a estabilidade da atitude de marca, assim como o ajuste (fit) entre 
patrocinador e o evento (HUETTERMANN et al., 2020). Essa consistência de uma forma geral, não só da atitude de marca, mostrou-se, segundo estudos recentes (HUETTERMANN et al., 2020), um indicador de patrocínios de sucesso, o que culminou em um reconhecimento e imagem de marca positivos.

Falta de consistência ou ajuste entre patrocinadores não endêmicos e patrocinado nos eSports pode trazer impactos negativos, pois levaria o consumidor a reconhecer tais patrocinadores como oportunistas (HUETTERMANN et al., 2020), como exemplificado pelo caso da MercedesBenz citado anteriormente. Todavia, certos estudos, como o de Gawrysiak et al. (2020) e Ströh (2017), indicam que os consumidores de eSports reconhecem que é preciso diversificar as parcerias para a indústria de eSports continuar crescendo isto é, faz-se necessário trazer patrocinadores fora do cenário de eSports. Assim, Huettermann et al. (2020) entendem que a atitude de marca de eSports impactará positivamente a atitude em relação ao patrocinador, pois ele poderia ser visto como parcialmente responsável pelo crescimento da indústria de eSports. Com base nisso, propõe a hipótese 2.a:

Hipótese 2.a.: A atitude de marca de eSports terá impactos positivos sobre a atitude com o patrocinador.

Acredita-se que a atitude da marca, ou envolvimento dos fãs para Dees et al. (2008), pode influenciar a intenção de compra de produtos do patrocinador (BISCAIA et al., 2017; DEES et al., 2008; HUETTERMANN et al., 2020). Como mencionado anteriormente, esse fato depende em muito da percepção de fit ou ajuste do patrocinador com a marca, que segundo Mazodier \& Quester (2014), é o grau em que o patrocinador e o patrocinado são vistos como similares, seja por conta de funcionalidade, atributos, imagens ou outras associações. Entretanto, Huettermann et al. (2020) apontam para o fato de que os consumidores de eSports podem ser considerados, muitas vezes, um público distinto dos consumidores de esportes tradicionais. Para os autores, isto sugere que os espectadores de eSports, podem ter uma percepção de fit menor entre patrocinadores não endêmicos e seus patrocinados. No entanto, ainda sim, para Huettermann et al. (2020), o fato do público de eSports ser jovem, com alto poder aquisitivo e sensíveis a novas tendências aumentaria consideravelmente as chances de serem influenciados 
positivamente para comprar produtos dos patrocinadores associados ao seu eSport/time preferido. Com base nessa ideia, propõem a hipótese $2 \mathrm{~b}$ :

Hipótese 2.b: A atitude de marca de eSports impactará positivamente a intenção de compra de produtos de patrocinadores não endêmicos.

\subsection{Percepção de boa vontade}

Segundo Rogers et al. (2020) a percepção de boa vontade (goodwill) é o cerne da diferença entre o patrocínio e a publicidade tradicional. É, também, o que transforma fãs em consumidores. Ainda segundo os autores, a percepção da audiência sobre a boa vontade dos patrocinadores motiva a ideia ou a noção de que os patrocinadores apoiam o evento e o tornam possível. "Isto é contrário às percepções sobre a publicidade tradicional, que são geralmente anúncios puramente para beneficiar o anunciante" (Ibid., p. 562).

Sendo assim, é esperado que a percepção de boa vontade do patrocinador tenha impactos positivos na atitude do consumidor em relação ao patrocinador. A percepção de boa vontade para Huettermann et al. (2020) está ligada intrinsecamente à percepção do consumidor de sinceridade na motivação do patrocinador ao realizar o patrocínio. Aqui o fator que mais importa é o envolvimento emocional do consumidor com o investimento do patrocinador, ou seja, quando um patrocínio é percebido como um ato de boa vontade, isso leva o consumidor a associações positivas com a marca (HUETTERMANN et al., 2020).

Deve-se atentar, entretanto, ao fato de que a percepção de boa vontade está também relacionada à percepção de fit patrocinador/patrocinado. Uma baixa percepção de fit poderia levar o público a perceber um patrocinador como oportunista, impactando negativamente na percepção de boa vontade (HUETTERMANN et al., 2020). Essa relação é especialmente perigosa para patrocinadores não endêmicos, que estão naturalmente sujeitos a percepções mais baixas de fit. Dito isso, Huettermann et al. (2020) apontam a possibilidade de que os consumidores poderiam interpretar a entrada de patrocinadores não endêmicos como um sinal de crescimento da indústria e possível aumento da aceitação social dos eSports, algo desejável. 
Assim, Huettermann et al. (2020) propõem a terceira hipótese:

Hipótese 3: A percepção de boa vontade sobre o patrocinador impactará positivamente a atitude em relação ao patrocinador.

\subsection{Atitude em relação ao patrocinador}

"A atitude do consumidor em relação ao patrocinador influencia diretamente a intenção de compra dos produtos do patrocinador" (HUETTERMANN et al., 2020, p.9). Vale ressaltar a importância da análise de intenção de compras quando falamos do comportamento do consumidor de eSports - os profissionais de marketing esportivo têm como principal objetivo gerar satisfação do consumidor, estabelecer fãs leais e, por fim, gerar compras repetidas (Ibid.).

Madrigal (2001) fez um estudo correlacionando a identificação de estudantes com os times de suas escolas. No estudo, analisaram-se suas crenças, atitudes e a intenção de comprar os produtos do patrocinador associado aos times de esportes convencionais de suas escolas. Este estudo mostrou que os estudantes que tinham forte identificação com o time da escola, tinham também mais propensão para comprar os produtos dos patrocinadores associados ao time do que aqueles estudantes que tinham pouca ou nenhuma identificação com os times. Dessa forma, concordando com Meenaghan (2001 apud HUETTERMANN, 2020): quanto mais engajado o consumidor, mais positiva será sua atitude para com o patrocinador. Além disso, Gardner \& Schuman (1987 apud HUETTERMANN, 2020) concluíram em sua pesquisa que a maioria dos respondentes comprou produtos da empresa patrocinadora por causa do patrocínio feito ao seu time. Por conseguinte, isso nos leva a hipótese 4:

Hipótese 4: A atitude sobre o patrocinador impactará positivamente a intenção de compra de produto do patrocinador. 


\section{METODOLOGIA}

Neste capítulo é descrita a metodologia adotada por este estudo. São explorados o tipo de pesquisa, os construtos utilizados, a população estudada, o processo de amostragem, as escalas de mensuração das variáveis e sua escolha, o método de coleta de dados, as técnicas e procedimentos de tratamento e análise dos dados e as limitações do método.

\subsection{Tipo de pesquisa}

Para testar as hipóteses propostas do Huettermann et al. (2020), no contexto do mercado brasileiro, foi conduzido um estudo transversal (MALHOTRA, 2006) com uma amostra não probabilística da população de interesse, embasado na tradução das questões usadas no estudo original. A pesquisa foi realizada por meio de questionários estruturados (MALHOTRA, 2006), via internet e autoadministrados, ou seja, enviados diretamente para o público desejado sem intermediários ou entrevistadores (AAKER et al., 2006). No início do questionário, os participantes foram informados do tema da pesquisa: a percepção do consumidor brasileiro sobre patrocinadores do setor. Também foi apresentada a definição, adotada neste estudo, de eSports: jogos eletrônicos competitivos e seus campeonatos. A participação foi voluntária; ou seja, não houve nenhum tipo de remuneração para os participantes.

\subsection{Operacionalização das variáveis}

O presente estudo usa escalas já elaboradas e testadas para a medição dos construtos relacionados aos motivos de consumo de mídia e efetividade de patrocínio. Foram utilizadas, no total, cinco escalas.

A primeira delas é a Escala de Motivação para Consumo de Esportes (EMCE), elaborada por Trail \& James (2001), composta por 31 itens, e amplamente utilizada na literatura dos esportes convencionais como um medidor válido de "spectator motives" (HUETTERMANN et al., 2020, p.11), ou seja, o motivo para assistir esportes. 
As quatro escalas restantes foram adaptadas a partir das escalas para medição de efetividade de patrocínio de Dees et al. (2008): atitude de marca (composta por 4 itens), percepção de boa vontade (composta por 3 itens), atitude em relação ao patrocinador (composta por 4 itens) e intenção de compra de produto do patrocinador (composta por 4 itens).

Para manter a consistência com o estudo original e assegurar que os participantes representavam uma amostragem de consumidores de eSports, foram adotadas duas questões de validação. A primeira pergunta de validação questionava se o participante assiste eSports e apresentava as opções de resposta de "Sim" ou "Não". A segunda pergunta questionava a frequência com que o participante assiste eSports, tendo como opções de resposta uma escala Likert com as seguintes opções para frequência: nunca, raramente, ocasionalmente, frequentemente e muito frequentemente. Adotando o critério de validação de Huettermann et al. (2020), só foram consideradas as respostas de participantes que afirmaram assistir eSports com no mínimo frequência ocasional, ou seja, que responderam "Sim" para a primeira questão e "Ocasionalmente", "Frequentemente" ou "Muito frequentemente" na segunda.

As escalas mencionadas anteriormente foram utilizadas neste estudo para manter coerência com as escolhas de Huettermann et al. (2020), que destaca a confiabilidade e amplo uso delas. Sendo assim, o instrumento de pesquisa resultante das escalas mencionadas conta com 46 questões de avaliação dos construtos, 5 questões relativas a variáveis demográficas e 2 questões de validação, totalizando 53 questões.

O questionário é dividido em três segmentos: motivos para assistir, avaliados pela EMCE, efetividade de patrocínio, avaliado pelas escalas de Dees et al. (2008) e demografia. No apêndice A, encontra-se o questionário em sua estrutura completa e traduzido. 


\subsubsection{Definição operacional das variáveis}

Na tabela 3.1 estão detalhadas as escalas usadas para medição de cada construto, bem como os itens do questionário que correspondem a cada escala (Apêndice A).

Tabela 3.1: Escalas e medidas operacionais para cada variável do instrumento de pesquisa

\begin{tabular}{|c|c|}
\hline Construto & Tipo de escala e medidas operacionais \\
\hline Variáveis Demográficas & Escala Categórica \\
\hline Idade & $\begin{array}{l}\text { Apêndice A, Questão 3: Abaixo de } 18,18 \text { a } \\
24,25 \text { a } 34,35 \text { a } 44,45 \text { a } 54,55 \text { ou mais }\end{array}$ \\
\hline Gênero & $\begin{array}{l}\text { Apêndice A, Questão 4: Masculino, } \\
\text { Feminino, não binário/terceiro gênero, } \\
\text { Prefere não dizer }\end{array}$ \\
\hline Faixa de Renda & $\begin{array}{l}\text { Apêndice A, Questão 5: Menos de dois } \\
\text { salários-mínimos, De dois a três salários- } \\
\text { mínimos, De três a quatro salários mínimos, } \\
\text { De quatro a cinco salários-mínimos, Acima } \\
\text { de cinco salários mínimos }\end{array}$ \\
\hline Escolaridade & 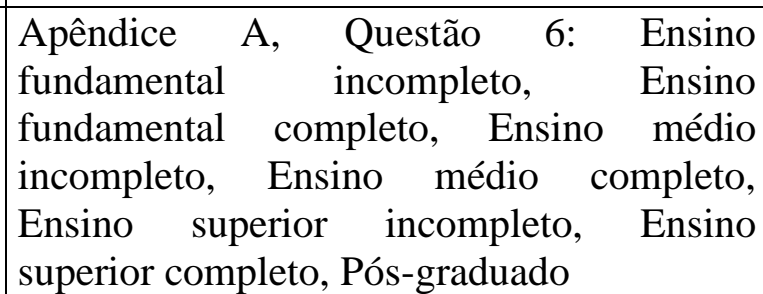 \\
\hline Ocupação & $\begin{array}{l}\text { Apêndice A, Questão 7: Empregado em } \\
\text { empo integral, empregado em meio } \\
\text { período, Dono(a) de casa, Estudante, } \\
\text { Desempregado, Outro }\end{array}$ \\
\hline EMCE & $\begin{array}{l}\text { Escala Likert de } 5 \text { pontos, adaptação para } \\
\text { português da escala de Trail et James } \\
(2001)\end{array}$ \\
\hline Conquista Vicária (CV) & Apêndice A, Questões 8, 9 e 10 \\
\hline Estética (EST) & Apêndice A, Questões 11,12 e 13 \\
\hline Drama (DR) & Apêndice A, Questões 14,15 e 16 \\
\hline Escapismo (ESC) & Apêndice A, Questões 17,18 e 19 \\
\hline Aquisição de Conhecimento (AC) & Apêndice A, Questões 20,21 e 22 \\
\hline Habilidades Físicas (HF) & Apêndice A, Questões 23, 24 e 25 \\
\hline Interação Social (IS) & Apêndice A, Questões 26, 27 e 28 \\
\hline Atratividade Física (AF) & Apêndice A, Questões 29, 30 e 31 \\
\hline Agressividade (AGR) & Apêndice A, Questões 32, 33, 34 e 35 \\
\hline Novidade (NOV) & Apêndice A, Questões 36, 37 e 38 \\
\hline \multirow{2}{*}{$\begin{array}{l}\text { Atitude de Marca de eSport } \\
\text { (AME) }\end{array}$} & $\begin{array}{l}\text { Escala Likert de } 5 \text { pontos, adaptação para } \\
\text { português da escala de Dees et al. (2008) }\end{array}$ \\
\hline & Apêndice A, Questões 39, 40, 41 e 42 \\
\hline
\end{tabular}




\begin{tabular}{|l|l|}
\hline Construto & Tipo de escala e medidas operacionais \\
\hline \multirow{2}{*}{ Percepção de Boa Vontade (PBV) } & $\begin{array}{l}\text { Escala Likert de 5 pontos, adaptação para } \\
\text { português da escala de Dees et al. (2008) }\end{array}$ \\
\cline { 2 - 2 } & Apêndice A, Questões 43, 44 e 45 \\
\hline $\begin{array}{l}\text { Atitude em Relação ao } \\
\text { Patrocinador (ARP) }\end{array}$ & $\begin{array}{l}\text { Escala Likert de 5 pontos, adaptação para } \\
\text { português da escala de Dees et al. (2008) }\end{array}$ \\
\cline { 2 - 2 } $\begin{array}{l}\text { Intenção de Compra de Produto do A, Questões 46, 47, 48 e 49 } \\
\text { Patrocinador (ICPP) }\end{array}$ & $\begin{array}{l}\text { Escala Likert de 5 pontos, adaptação para } \\
\text { português da escala de Dees et al. (2008) }\end{array}$ \\
\cline { 2 - 2 } & Apêndice A, Questões 50, 51, 52 e 53 \\
\hline
\end{tabular}

\subsubsection{Procedimentos de tradução e adaptação das escalas utilizadas}

As escalas utilizadas neste presente estudo foram, sem exceção, desenvolvidas para a língua inglesa. Por esse motivo, tornou-se necessária a realização de tradução e adaptação de cada uma para a língua portuguesa, tornando-as acessíveis para o público brasileiro.

Segundo Sperber (2004), a adaptação de escalas de um idioma para outro deve seguir múltiplas etapas. Inicialmente, cada um dos itens de cada escala foi traduzido de forma independente por um indivíduo fluente na língua inglesa e nativo da língua portuguesa. Após esse passo, foi realizada a retradução ou backtranslation para o inglês por dois estudantes fluentes na língua inglesa e nativos da língua portuguesa. As traduções resultantes se mostraram conceitualmente equivalentes às escalas originais, validando a tradução original.

\subsubsection{Pré-teste do instrumento de pesquisa}

Com o resultado da tradução original validado, os itens foram incluídos no instrumento de pesquisa com o intuito de realizar um pré-teste. Na primeira leva de pré-testes, uma pequena amostra da população desejada preencheu o questionário sob supervisão, com a orientação de que qualquer dúvida, dificuldade de compreensão ou interpretação e sugestões de melhorias fossem identificadas.

Os feedbacks desta primeira fase de pré-testes serviram como guia para aprimorar o instrumento de pesquisa. Uma nova versão foi elaborada e testada 
novamente com 11 membros da população desejada, mais uma vez buscando pontos de melhorias. Com os retornos obtidos nesta segunda rodada de testes foi elaborado o modelo final do instrumento de pesquisa, exposto no Apêndice A.

\subsection{População e amostra}

\subsubsection{População}

A população-alvo estudada foi a de brasileiros consumidores regulares de eSports. Esta população foi delineada segundo os critérios de validação de Huettermann et al. (2020), por meio das questões de validação previamente discutidas que serviram para qualificar respondentes que assistem eSports com, pelo menos, frequência média, segundo medição por escala Likert de 5 pontos (frequência "ocasionalmente" ou maior).

\subsubsection{Amostra}

Segundo Parasuraman et al. (2006), para realizar-se uma seleção aleatória correta, toda a população-alvo de um estudo deve ser acessada. Como não é factível o acesso a todos os brasileiros que consomem eSports regularmente, foi realizada uma amostragem não probabilística por conveniência. Malhotra (2006) aponta que, em amostragens não probabilísticas, não há maneira de determinar a probabilidade de escolha de qualquer elemento em particular para inclusão na amostra. O autor destaca também que amostras por conveniência buscam elementos cujo acesso é conveniente, isto é, os entrevistados são escolhidos por estarem disponíveis no lugar e momento certos.

A amostra obtida foi de 408 respondentes, dos quais 83 foram eliminados por não terem completado o formulário e 123 foram eliminados por não se qualificarem segundo os critérios de validação de Huettermann et al. (2020), não se encaixando, portanto, no público-alvo. Assim, a amostra final foi composta por 202 questionários válidos. 
Segundo Hair et al. (2009), na utilização de modelagem de equações estruturais, o número de entradas válidas deve exceder o número de covariâncias somado ao de variâncias na matriz de entrada de dados. Isso pode ser calculado pela fórmula $\mathrm{N}^{*}(\mathrm{~N}+1) / 2$, onde $\mathrm{N}$ é o número de variáveis observáveis no modelo explicativo, de forma que o resultado não deve ser inferior ao número mínimo de 200 entradas.

\subsection{Coleta de dados}

\subsubsection{O instrumento de coleta de dados}

Conforme descrito no tópico 3.2, o instrumento de pesquisa foi composto por 53 itens, sendo 31 deles referentes ao construto motivo para assistir eSports, medido pela EMCE e 15 deles referentes aos construtos atitude de marca, percepção de boa vontade, atitude em relação ao patrocinador e intenção de compra de produto do patrocinador, medidos pelas escalas de Dees et al. (2008). Dos sete itens remanescentes, dois referenciam os critérios de validação Huettermann et al. (2020) e cinco mediam variáveis demográficas dos respondentes.

Quanto à estrutura do questionário, inicia-se com as questões de validação seguidas pelos itens de medição de variáveis demográficas. Em seguida, respondem-se os itens referentes ao construto motivação para consumo de eSports. Seguem-se então os itens relativos aos construtos atitude de marca, percepção de boa vontade, atitude em relação ao patrocinador e intenção de compra de produto do patrocinador.

\subsubsection{A coleta de dados}

Todos os dados foram colhidos na internet via questionários autoadministrados online na plataforma Qualtrics. Os questionários foram divulgados, via link de acesso à página no Qualtrics, entre setembro e outubro de 
2021 nas plataformas WhatsApp, Instagram, em aulas online das faculdades PUCRio, UFRJ e UFF, grupos de empresas júnior, comunidades brasileiras no Reddit e servidores brasileiros sobre eSports diversos no Discord.

\subsection{Análise dos dados}

Os dados obtidos pelo instrumento de pesquisa foram reproduzidos para processamento estatístico em bases de dados SPSS. Os softwares SPSS e AMOS foram utilizados para realizar as análises estatísticas univariadas e multivariadas dos dados obtidos.

Primeiramente, foram excluídos da amostra participantes que não responderam o questionário em sua totalidade, ou seja, que apresentavam valores ausentes. Nesta etapa foram eliminados 83 respondentes. Depois foi realizada uma análise descritiva dos critérios de validação de Huettermann et al. (2020) incluídos nas primeiras duas questões do formulário, de forma a eliminar participantes que não se enquadraram no perfil do público-alvo. Nesta etapa foram eliminados 123 respondentes que não se classificaram como consumidores regulares de eSports.

Desta forma, chegou-se à base de dados final, com 202 participantes classificados como consumidores regulares de eSports e que responderam a todos os itens do questionário.

\subsubsection{Validade e Confiabilidade}

A partir da base de dados final, foi realizada uma análise fatorial confirmatória (CFA) com o objetivo de estimar o modelo de mensuração e avaliar as características dos construtos incluídos no instrumento de pesquisa, em especial aos fatores unidimensionalidade, confiabilidade e validade.

Segundo Hair et al. (2009) e Churchill (1979), a validade de um construto pode ser definida como o grau de efetividade pelo qual uma escala reflete o construto latente que ela se dispõe a medir, enquanto a confiabilidade (indicador de validade convergente) pode ser definida como o grau de consistência que uma 
variável ou conjunto de variáveis apresenta em relação ao que se deseja medir. Os construtos presentes neste instrumento foram avaliados pelo método do Alfa de Cronbach (NUNNALLY, 1978, apud FERREIRA, 2010) e da confiabilidade composta. Desta forma, valores de confiabilidade composta e do Alfa de Cronbach maiores que 0,8 são considerados adequados, enquanto valores acima de 0,7 são considerados aceitáveis (HAIR et al., 2009; NUNNALLY; BERNSTEIN, 1994).

As validades dos construtos (nomológica, convergente e discriminante) foram avaliadas pelo exame da correlação entre construtos resultantes da CFA realizada e das cargas fatoriais internas de cada construto, pela variância extraída média (Average Variance Extracted ou AVE) e pela matriz de validade discriminante - que contém a AVE na diagonal principal e as correlações ao quadrado entre os construtos nas demais células (FORNELL; LARCKER, 1981; HAIR et al., 2009)

\subsubsection{Análises Estatísticas}

O teste das 5 hipóteses apresentadas por Huettermann et al. (2020) foi realizado por meio de modelagem de equações estruturais (SEM), utilizando o software AMOS 18.0. O uso deste tipo de análise é adequado às questões desta pesquisa e às hipóteses formuladas pois permite a estimação de relações simultâneas entre variáveis, sejam elas dependentes ou independentes (FERREIRA, 2010). Segundo Hair et al. (2009), a utilização desta técnica possibilita a avaliação simultânea dos efeitos de todos os construtos do modelo proposto, evitando distorções que poderiam ocorrer nas dependências observadas entre as variáveis, caso fossem estudadas independentemente.

Para estimar o modelo de equações estruturais, o método de estimação por máxima verossimilhança (Maximum Likelihood ou ML) foi utilizado. Foi utilizada a abordagem de dois estágios para modelagem de equações estruturais recomendada por Anderson \& Gerbing (1988). Para a avaliação do ajuste dos modelos de CFA e SEM foram utilizados os índices de ajuste recomendados por Garver \& Mentzer (1999) e Hair et al. (2009): o Tucker-Lewis Index (TLI ou 
NNFI), o Comparative Fit Index (CFI), o Root Mean Square Approximation Error (RMSEA) e a estatística qui-quadrada do modelo (juntamente com os graus de liberdade associados). Todos esses índices (com exceção da estatística quiquadrada) são de fácil interpretação por estarem em uma escala contínua de 0 a 1 e são relativamente independentes de efeitos ligados ao tamanho da amostra (FERREIRA, 2010). Segundo Hair et al. (2009), índices como o Goodness-of-Fit Index (GFI) e o Adjusted Goodness-of-Fit Index (AGFI) se tornaram obsoletos devido a sua sensibilidade ao tamanho da amostra e à complexidade do modelo. Estes índices, portanto, não serão utilizados.

\subsection{Limitações do método}

\subsubsection{Limitações relacionadas ao critério de amostragem}

Dado o fato de ter sido realizada uma amostra não probabilística por conveniência, existem perdas na representatividade da amostra em relação à população-alvo. Neste modelo de amostragem, estão presentes muitas fontes potenciais de viés de seleção, inclusive a auto seleção dos entrevistados (MALHOTRA, 2006, p. 326). Além disso, não foi criado um método para verificar se, de fato, os entrevistados são íntimos com cenário de eSports, seja como espectador ou participante.

\subsubsection{Limitações decorrentes da coleta de dados}

Primeiramente, o questionário tem certa limitação, pois não pede para o entrevistado informar qual eSport específico ele acompanha. Por conta disso, perde-se a chance de avaliar as possíveis diferenças na medição dos construtos entre espectadores de eSports distintos, criando-se uma imagem generalizada do público consumidor de eSports.

Outra limitação importante foi a indisponibilidade de algumas vias de acesso ao público-alvo. O contexto de pandemia em que a pesquisa foi realizada 
impediu a divulgação dos questionários em eventos de eSports, como competições e convenções. Além disso, muitos sites e plataformas como a Twitch.tv, Instagram e Facebook não permitem a divulgação de links externos. Estes quatro exemplos de vias indisponíveis limitam em muito o acesso ao público-alvo, visto que eventos de eSports, transmissões de eSports na Twitch.tv e contas de influencers e grupos de eSports no Facebook e páginas no Instagram representam janelas diretas ao consumidor de eSports. 


\section{MODELAGEM E ANÁLISE DOS DADOS}

Neste capítulo são apresentadas as características estatísticas e psicométricas da amostra final, o ajuste dos modelos de mensuração e estruturais propostos é realizado e são testadas as hipóteses da pesquisa.

\subsection{Caracterização da amostra}

Durante seis semanas, entre o meio de setembro e o fim de outubro de 2021, o instrumento de pesquisa (Apêndice A) foi divulgado, totalizando uma amostra de 408 participantes. A participação foi confidencial e voluntária.

Conforme mencionado no Capítulo 3, da amostra inicial de 408 respondentes, 83 foram eliminados por não terem preenchido o questionário completamente e 123 foram eliminados por não se qualificarem como consumidores regulares de eSports segundo os critérios de validação de Huettermann et al. (2020). Desta forma, a amostra final foi composta por 202 questionários válidos.

A tabela 4.1 ilustra as características demográficas da amostra final, obtidas por meio de cinco questões, abrangendo: faixa etária, gênero, faixa de renda, grau de escolaridade e ocupação. Enquanto todas as faixas etárias foram representadas na pesquisa, a vasta maioria dos participantes responderam ter entre 18 e $34 \operatorname{anos}(n=176,87,1 \%)$. Os participantes foram, em vasta maioria, do gênero masculino ( $n=183,90,6 \%)$, seguido pelo gênero feminino $(n=17,8,4 \%)$ e não binários/terceiro gênero $(n=2,1 \%)$. Quanto à faixa de renda, a maioria afirmou receber menos de dois salários-mínimos $(n=69,34,2 \%)$, seguido por acima de cinco salários-mínimos $(\mathrm{n}=57,28,2 \%)$ e depois entre dois e três salários-mínimos $(\mathrm{n}=42,20,8 \%)$. Já quanto à escolaridade e ocupação, a maior parte dos respondentes possui ensino superior incompleto $(n=97,48 \%)$ e é estudante $(n=94$, $46,5 \%)$. 
Tabela 4.1: Características Demográficas

\begin{tabular}{|c|c|c|c|}
\hline Variável & Categoria & $\mathrm{n}$ & $\%$ \\
\hline \multirow[t]{6}{*}{ Idade } & Abaixo de 18 & 16 & 7,9 \\
\hline & 18 a 24 & 103 & 51,0 \\
\hline & 25 a 34 & 73 & 36,1 \\
\hline & 35 a 44 & 6 & 3,0 \\
\hline & 45 a 54 & 3 & 1,5 \\
\hline & 55 ou mais & 1 & 0,5 \\
\hline \multirow[t]{3}{*}{ Gênero } & Feminino & 17 & 8,4 \\
\hline & Masculino & 183 & 90,6 \\
\hline & Não binário/terceiro gênero & 2 & 1,0 \\
\hline \multirow[t]{5}{*}{ Faixa de Renda } & Acima de cinco salários-mínimos & 57 & 28,2 \\
\hline & De dois a três salários-mínimos & 42 & 20,8 \\
\hline & De quatro a cinco salários-mínimos & 11 & 5,4 \\
\hline & De três a quatro salários-mínimos & 23 & 11,4 \\
\hline & Menos de dois salários-mínimos & 69 & 34,2 \\
\hline \multirow[t]{7}{*}{ Grau de Escolaridade } & Ensino fundamental completo & 3 & 1,5 \\
\hline & Ensino fundamental incompleto & 1 & 0,5 \\
\hline & Ensino médio completo & 36 & 17,8 \\
\hline & Ensino médio incompleto & 10 & 5,0 \\
\hline & Ensino superior completo & 37 & 18,3 \\
\hline & Ensino superior incompleto & 97 & 48,0 \\
\hline & Pós-graduado & 18 & 8,9 \\
\hline \multirow[t]{7}{*}{ Ocupação } & Desempregado & 14 & 6,9 \\
\hline & Dono(a) de casa & 1 & 0,5 \\
\hline & Empregado em meio período & 19 & 9,4 \\
\hline & Empregado em tempo integral & 59 & 29,2 \\
\hline & Estudante & 94 & 46,5 \\
\hline & Outro & 15 & 7,4 \\
\hline & Total & 202 & \\
\hline
\end{tabular}




\subsection{Análises e resultados}

\subsubsection{Avaliação do Modelo de Mensuração}

O modelo de mensuração define as relações entre as variáveis observadas e os construtos latentes não observados, permitindo a avaliação de quanto cada item medido se relaciona com cada fator em particular (FERREIRA, 2010, p.107). No intuito de testar a validade, unidimensionalidade e confiabilidade das escalas utilizadas no modelo de mensuração, foi realizada uma análise fatorial confirmatória (CFA).

Para avaliar o ajuste do modelo de mensuração proposto, diversos índices de ajuste foram utilizados (tanto incrementais, quanto absolutos), uma vez que não existe consenso na literatura sobre qual índice (ou conjunto de índices) deve ser utilizado para checar o ajuste de modelos desta natureza (FERREIRA, 2010). O modelo de mensuração testado apresenta os índices de ajuste apontados na tabela 4.2. Em conjunto, esses índices finais sugerem um ajuste satisfatório dos dados para o modelo proposto (HU; BENTLER, 1999; SCHREIBER et al., 2006).

Tabela 4.2: Índices de Ajuste (Fit) do Modelo de Mensuração

\begin{tabular}{|c|c|c|}
\hline Índice de Ajuste & Modelo Proposto & $\begin{array}{c}\text { Valor sugerido pela } \\
\text { literatura }\end{array}$ \\
\hline$\chi^{2 / \text { d.f. }}$ & 1,59 & $\leq 3$ \\
\hline CFI & 0,90 & $\geq 0,90$ \\
\hline TLI & 0,90 & $\geq 0,90$ \\
\hline IFI & 0,91 & $\geq 0,90$ \\
\hline RMSEA & 0,05 & $\leq 0,08$ \\
\hline SRMR & 0,06 & $\leq 0,08$ \\
\hline
\end{tabular}




\title{
4.2.2. Validade e Confiabilidade dos Construtos
}

A validade de um construto pode ser desmembrada em quatro componentes individuais: validade convergente, validade discriminante, validade de face e validade nomológica (HAIR et al., 2009).

Segundo Ferreira (2010, p.109), a validade de face determina a consistência do conteúdo de cada item com o construto que ele mede. Considerando que todas as escalas utilizadas já estão em uso difundido na literatura (HUETTERMANN et al., 2010), foram traduzidas criteriosamente e testadas com amostras da população de interesse, pode-se considerar que a validade de face foi garantida.

Ainda segundo Ferreira (2010, p.109):

\begin{abstract}
A validade nomológica, por sua vez, examina se as correlações entre os construtos da teoria de mensuração aplicada fazem sentido. Uma maneira de analisar a validade nomológica é avaliar a matriz de correlação entre construtos, com o intuito de verificar se os construtos se relacionam entre si de acordo com o previsto pela teoria.
\end{abstract}

De acordo com a revisão de literatura realizada para este estudo (HUETTERMANN et al., 2020; TRAIL; JAMES, 2001), é esperado que a EMCE possua uma relação positiva com atitude de marca de eSports e que esta, e a percepção de boa vontade, apresentem relações positivas com a atitude em relação ao patrocinador. Por sua vez, é esperado que a atitude em relação ao patrocinador, juntamente com a atitude de marca de eSports tenham correlações positivas com a intenção de compra de produto do patrocinador (HUETTERMAN et al., 2020; TRAIL; JAMES, 2001; BISCAIA et al., 2017).

O quadro 4.1 apresenta a matriz de correlação entre todos os construtos estudados. 
Quadro 4.1: Matriz de Correlação entre Construtos

\begin{tabular}{|l|c|c|c|c|c|}
\cline { 2 - 6 } & EMCE & $\begin{array}{c}\text { Boa } \\
\text { Vontade }\end{array}$ & $\begin{array}{c}\text { Atitude } \\
\text { Marca }\end{array}$ & $\begin{array}{c}\text { Atitude } \\
\text { Patrocinador }\end{array}$ & $\begin{array}{c}\text { Intenção } \\
\text { de Compra }\end{array}$ \\
\hline EMCE & 1 & 0,376 & 0,334 & 0,242 & 0,219 \\
\hline $\begin{array}{l}\text { Boa } \\
\text { Vontade }\end{array}$ & 0,376 & 1 & 0,321 & 0,579 & 0,545 \\
\hline $\begin{array}{l}\text { Atitude } \\
\text { Marca }\end{array}$ & 0,334 & 0,321 & 1 & 0,363 & 0,331 \\
\hline $\begin{array}{l}\text { Atitude } \\
\text { Patrocinador }\end{array}$ & 0,242 & 0,579 & 0,363 & 1 & 0,698 \\
\hline $\begin{array}{l}\text { Intenção de } \\
\text { Compra }\end{array}$ & 0,219 & 0,545 & 0,331 & 0698 & 1 \\
\hline
\end{tabular}

Todas as correlações expostas no quadro 4.1 foram positivas e significativas a um nível de significância de 0,001, conforme esperado pela literatura. Assim, pode-se concluir que os construtos utilizados apresentam validade nomológica.

Quanto à consistência interna e a confiabilidade das escalas utilizadas, na tabela 4.3 estão descritos os coeficientes alfa de Cronbach calculados para as escalas utilizadas e as confiabilidades compostas para cada construto. De acordo com a literatura, coeficientes alfas maiores do que 0,8 são considerados bons, enquanto coeficientes entre 0,7 e 0,8 são considerados aceitáveis (NUNNALLY; BERNSTEIN, 1994; FORNELL; LARCKER, 1981; HAIR et al., 2009). Quanto à confiabilidade composta, indicadora da consistência interna de indicadores que medem um mesmo fator (FORNELL; LARCKER, 1981), a recomendação é de níveis acima de 0,7. Como descrito na tabela 4.3, todas as escalas utilizadas 
atendem aos níveis mínimos de confiabilidade considerados adequados pela literatura, apresentando valores acima de 0,7 tanto para o coeficiente alfa quanto para a confiabilidade composta.

Para avaliar validade convergente, foi calculada a variância extraída média para cada construto (Average Variance Extracted ou AVE). Os resultados são apresentados na tabela 4.3. Segundo Fornell \& Larcker (1981), estimativas de AVE maiores do que 0,50 indicam validade convergente adequada. Todos os valores de AVE calculados estão entre 0,50 e 0,82, evidenciando a validade convergente das escalas utilizadas.

Tabela 4.3- Confiabilidade, Confiabilidade Composta e Variância Extraída Média (AVE)

\begin{tabular}{l|c|c|c}
\hline Construto & Confiabilidade $(\alpha)$ & $\begin{array}{c}\text { Confiabilidade } \\
\text { Composta }\end{array}$ & AVE \\
\hline
\end{tabular}

$\begin{array}{llll}\text { EMCE } & 0,87 & 0,85 & 0,68\end{array}$

$\begin{array}{lll}\text { Boa Vontade } \quad 0,70 & 0,71 & 0,50\end{array}$

$\begin{array}{llll}\text { Atitude Marca } & 0,80 & 0,81 & 0,81\end{array}$

$\begin{array}{llll}\text { Atitude Patrocinador } & 0,80 & 0,82 & 0,82\end{array}$

Intenção de Compra $\quad 0,91 \quad 0,91 \quad 0,72$

Para avaliar a validade discriminante, deve-se certificar de que os itens se relacionam mais fortemente com os construtos que devem medir do que com outros construtos presentes no instrumento, ou seja, a variância compartilhada entre os itens de cada construto de ser maior que a variância compartilhada entre o construto e os demais construtos (FERREIRA, 2010). Fornell \& Larcker (1981) sugerem, para a avaliação da validade discriminante, que as variâncias extraídas médias (AVE) de cada construto sejam comparadas com as variâncias 
compartilhadas (o quadrado do coeficiente de correlação) entre todos os pares de construtos.

No quadro 4.2 encontra-se uma matriz para a análise da validade discriminante, onde a diagonal principal apresenta a AVE para cada construto e as células restantes representam o quadrado dos coeficientes de correlação entre cada par de construtos. Pela análise deste quadro, pode-se observar que todas as variâncias compartilhadas são menores que a variância extraída pelos itens que medem os construtos, indicando validade discriminante adequada.

Por fim, pela análise coletiva dos resultados apresentados para a análise fatorial confirmatória, julga-se que o modelo de mensuração proposto atende os requisitos necessários de confiabilidade, unidimensionalidade, validade de face, validade nomológica, validade convergente e validade discriminante. Desta forma, é possível a investigação das relações entre os construtos latentes por meio de um modelo estrutural.

Quadro 4.2: Matriz de Validade Discriminante

\begin{tabular}{|l|c|c|c|c|c|}
\cline { 2 - 6 } & EMCE & $\begin{array}{l}\text { Boa } \\
\text { Vontade }\end{array}$ & $\begin{array}{l}\text { Atitude } \\
\text { Marca }\end{array}$ & $\begin{array}{l}\text { Atitude } \\
\text { Patrocinador }\end{array}$ & $\begin{array}{l}\text { Intenção de } \\
\text { Compra }\end{array}$ \\
\hline EMCE & 0,68 & 0,14 & 0,11 & 0,06 & 0,04 \\
\hline Boa Vontade & 0,14 & 0,50 & 0,10 & 0,33 & 0,30 \\
\hline Atitude Marca & 0,11 & 0,10 & 0,81 & 0,12 & 0,11 \\
\hline $\begin{array}{l}\text { Atitude } \\
\text { Patrocinador }\end{array}$ & 0,06 & 0,33 & 0,12 & 0,82 & 0,49 \\
\hline $\begin{array}{l}\text { Intenção } \\
\text { Compra }\end{array}$ & 0,04 & 0,30 & 0,11 & 0,49 & 0,72 \\
\hline
\end{tabular}




\subsubsection{Teste das Hipóteses de Pesquisa}

A verificação das hipóteses da pesquisa foi realizada por meio da análise da magnitude, direção e significância dos coeficientes padronizados estimados por meio do modelo estrutural (BYRNE, 2010). As relações foram consideradas significativas se o $p$-value para o teste $\mathrm{t}$ associado ao coeficiente estimado de cada uma foi inferior a um nível de significância de 0,05 (BYRNE, 2010; HAIR et al., 2009). Os coeficientes estimados para o modelo proposto, as hipóteses de pesquisa e as significâncias associadas, estão listados na tabela 4.4 e ilustrados na figura 4.1.

Tabela 4.4: Coeficientes Padronizados Estimados, Hipóteses e Significâncias

\begin{tabular}{l|l|l|l}
\hline Relação Proposta & $\begin{array}{l}\text { Coeficiente } \\
\text { Padronizado }\end{array}$ & $p$-value & Hipótese Verificada \\
\hline
\end{tabular}

H1: EMCE $>$ Atitude Marca $\quad 0,542 \quad<0,001 \quad$ SIM

H2a: Atitude Marca > Atitude

Patrocinador

$0,267<0,001 \quad$ SIM

H2b: Atitude Marca > Intenção de Compra

$0,041 \quad 0,527 \quad \mathrm{NÃO}$

H3: Boa Vontade > Atitude

Patrocinador

$0,633<0,001 \quad$ SIM

H4: Atitude Patrocinador > Intenção de Compra $0,733<0,001 \quad$ SIM 
Pela análise dos resultados presentes na tabela 4.4 e na figura 4.1 , pode-se observar que foi obtido suporte empírico para 4 das 5 hipóteses de pesquisa formuladas, com relações significativas entre os construtos relacionados sendo observadas no modelo estrutural proposto. Os efeitos representados pelas hipóteses H1, H2a, H3 e H4 foram considerados significativos (p-value< 0,001). Desta forma, foram verificadas:

- A Hipótese 1, que afirmava que os motivos para assistir eSports teriam efeitos positivos sobre a atitude de marca de eSports;

- a Hipótese 2a, que afirmava que a atitude de marca de eSports teria efeitos positivos sobre a atitude em relação ao patrocinador;

- a Hipótese 3, que afirmava que a percepção de boa vontade teria efeitos positivos sobre a atitude em relação ao patrocinador;

- a Hipótese 4, que afirmava que a atitude de marca de eSports teria efeitos positivos sobre a intenção de compra de produto do patrocinador.

As relações entre estes efeitos e a comprovação destas hipóteses corroboram os resultados encontrados por Huettermann et al. (2020). Além disso, fortalecem a ideia de que os motivos para assistir eSports, medidos pela EMCE (TRAIL; JAMES, 2001), influenciam na atitude de marca de eSports. A atitude em relação ao patrocinador, por sua vez, parece influenciar positivamente na intenção de compra do produto do patrocinador e ser influenciada positivamente pela percepção de boa vontade e a atitude de marca de eSports. 


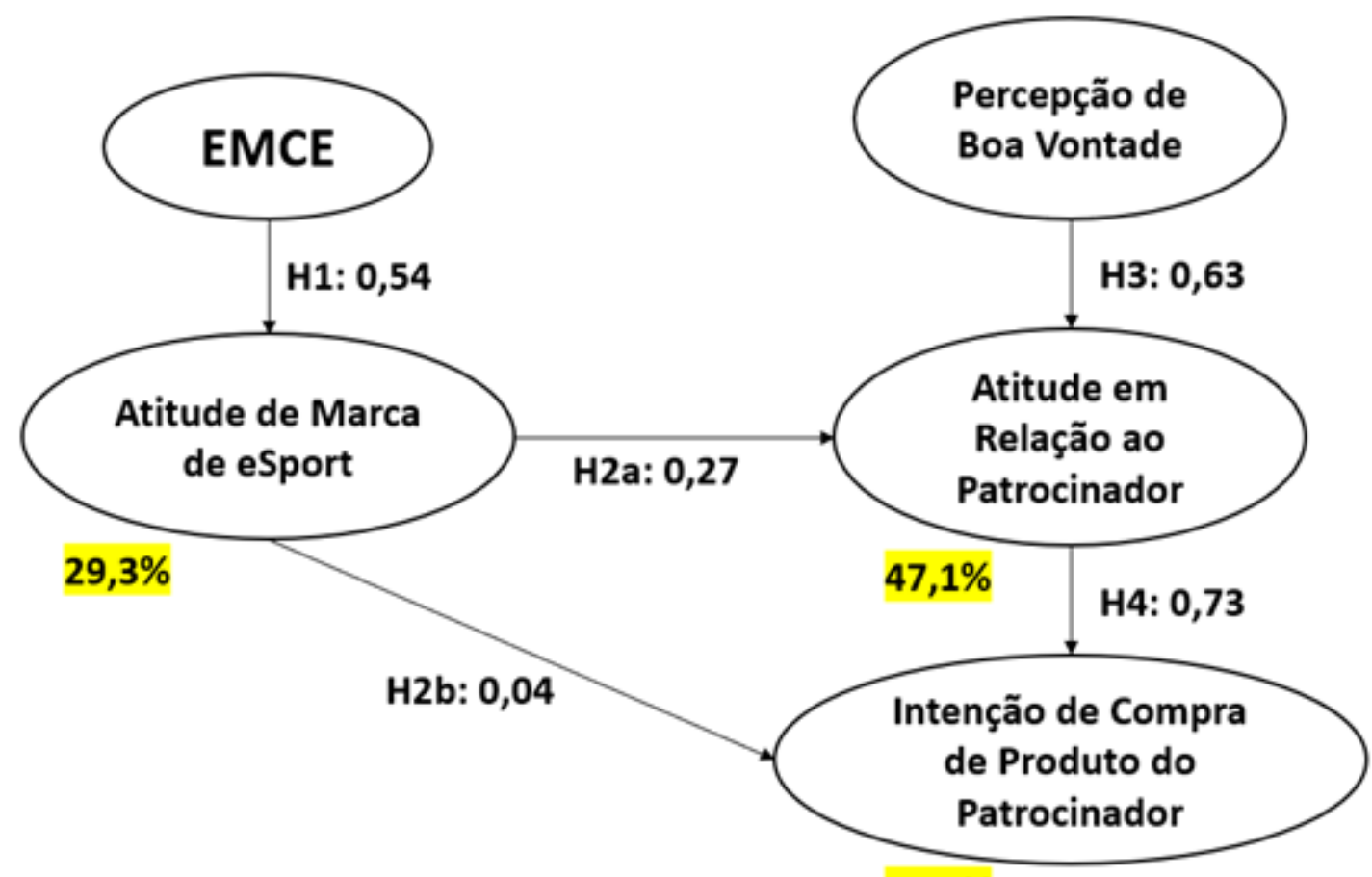

$55,6 \%$

Figura 4.1: Coeficientes Padronizados Estimados e proporção da variância explicada das variáveis dependentes para o modelo de Huettermann et al. (2020)

A hipótese 2b, “A atitude de marca de eSport impactará positivamente a intenção de compra de produtos do patrocinador", entretanto, não foi verificada. Os efeitos diretos da atitude de marca de eSports se mostraram fracos e não significativos (coeficiente padronizado de 0,041, p-value $=0,527$ ).

Por fim, destacam-se a força dos efeitos positivos entre a percepção de boa vontade e a atitude em relação ao patrocinador (coeficiente padronizado de 0,63 ) e entre e a atitude em relação ao patrocinador e intenção de compra de produto do patrocinador (coeficiente padronizado de 0,73). A atitude de marca de eSport mostrou um efeito mais fraco sobre a atitude em relação ao patrocinador (coeficiente padronizado de 0,27 ). Conclui-se que o efeito mais forte sobre a intenção de compra de produtos do patrocinador por parte do público-alvo é a atitude em relação ao mesmo. Desta forma, a atitude de marca de eSport mostra-se efetiva sobre a intenção de compra somente indiretamente, por meio de sua influência sobre a atitude em relação ao patrocinador, o que difere dos achados de Huettermann et al. (2020), que encontraram uma correlação média para o mesmo efeito (coeficiente padronizado 0,53). 


\subsection{Discussão dos resultados}

Nesta seção, são discutidos os resultados da pesquisa e suas implicações. Este trabalho se propôs a replicar o estudo de Huettermann et al. (2020) no contexto brasileiro, buscando entender se os mesmos efeitos das percepções dos consumidores de eSports sobre a intenção de compra de produtos dos patrocinadores encontrados pelos autores podem ser observados no público consumidor de eSports brasileiro.

Os resultados apresentados comprovam um bom ajuste do modelo de Huettermann et al. (2020) e fornecem evidências da relevância das relações propostas entre a intenção de compra de produto do patrocinador e as atitudes de marca de eSports e em relação ao patrocinador. Também é digna de nota a capacidade do modelo de explicar a intenção de compra do produto do patrocinador, medida por sua variância explicada em um valor de 55,6\%.

Tratando-se das hipóteses da pesquisa, 4 das 5 hipóteses propostas por Huettermann et al. (2020) foram verificadas. A tabela 4.5 apresenta um resumo dos resultados encontrados para cada hipótese.

Tabela 4.5: Resumo dos Resultados dos Testes de Hipóteses

Hipótese de Pesquisa

Hipótese Verificada

H1: Os motivos para consumo de eSports impactarão

$\operatorname{Sim}$ positivamente a atitude de marca de eSports.

H2.a: A atitude de marca de eSports impactará $\operatorname{Sim}$ positivamente a atitude sobre o patrocinador.

H2.b: A atitude de marca de eSports impactará Não positivamente a intenção de compra de produtos de patrocinadores não endêmicos tanto diretamente, quanto indiretamente, por meio da atitude em relação ao patrocinador. 
H3: A percepção de boa vontade sobre o patrocinador Sim impactará positivamente a atitude em relação ao patrocinador.

H4: A atitude sobre o patrocinador impactará $\operatorname{Sim}$ positivamente a intenção de compra de produto do patrocinador.

\subsubsection{Influência dos Motivos para Assistir eSports na Atitude de Marca de eSports}

Os resultados obtidos pela modelagem indicam que os motivos para assistir eSports, medidos pela EMCE (TRAIL; JAMES, 2001) representam um razoável $(0,542)$ e significativo $(p$-value $<0,001)$ antecedente para a formação de atitude de marca. Em outras palavras, os dados sugerem que consumidores que se sentem mais motivados para assistir eSports, ou os assistem com maior frequência, apresentam de fato atitudes de marca mais positivas em relação aos eSports. Estes resultados corroboram os efeitos observados por Huettermann et al. (2020) em sua pesquisa quando aplicados à população brasileira.

Embora a hipótese 1 em si tenha sido verificada, apoiando a ideia de que os dez motivos presentes na EMCE impactam positivamente a atitude de marca, é importante observar que estes explicaram somente $29.3 \%$ da variância no construto. Além disso, tanto o coeficiente padronizado quanto a variância foram menores do que os que Huettermann et al. (2020) encontraram para esta relação, sendo estes 0.864 e $74.7 \%$.

Dois construtos da EMCE em particular apresentaram um efeito neutro ou negativo como motivos para assistir eSports. Nas perguntas que mediam a conquista vicária (construto que descreve a necessidade de associar-se a entidades tidas como bem-sucedidas) como motivação para assistir eSports, mais da metade das respostas foram neutras ("não concordo nem discordo", $n=306,50,5 \%$ do total). Já nas perguntas que mediam a atratividade física dos jogadores como motivação para assistir eSports, as respostas foram majoritariamente negativas, com $62 \%$ dos respondentes escolhendo a opção "discordo totalmente" e 19\% 
escolhendo a opção "discordo". Juntas, estas duas opções representaram 82\% dos respondentes. Uma hipótese para explicar a neutralidade obtida nas questões sobre conquista vicária é a natureza subjetiva das questões que se propõe a medi-las (Apêndice A). Por tratarem de conceitos como autoestima, autovalorização e respeito próprio, estas questões podem ter causado dúvidas nos respondentes, assim criando uma tendência à neutralidade.

Já em relação às perguntas que mediam atratividade física dos jogadores como motivo, é provável que o fato de a amostra final ter sido composta por respondentes majoritariamente do gênero masculino $(90,6 \%)$ e tratarem de um cenário dominado por jogadores profissionais também do gênero masculino, tenha causado o nível de reações negativas observado. Assumindo que a parcela da amostra masculina seja composta majoritariamente por heterossexuais, esse tipo de resposta se tornaria previsível. A inclusão de uma questão pedindo para os respondentes identificarem sua sexualidade (com opções de resposta como: heterossexual, homossexual, bissexual, pansexual e assexual) na sessão demográfica do questionário ajudaria a comprovar esta hipótese.

Deve-se destacar que, o estudo original, de Huettermann et al. (2020), inclui em sua modelagem estatística os efeitos diretos de cada construto presente na EMCE sobre a atitude de marca de eSports. Como neste estudo a EMCE foi tratada como um construto de segunda ordem, esta análise foi aqui omitida.

\subsubsection{Influência da Atitude de Marca de eSports e da Percepção de Boa Vontade na Atitude em Relação ao Patrocinador}

Diversos autores indicaram em seus estudos que a atitude de marca teria efeito direto sobre a atitude em relação ao patrocinador (HUETTERMANN et al., 2020; BISCAIA et al., 2017). Estas hipóteses são aqui corroboradas pela verificação da hipótese $2 \mathrm{a}$, que aponta a presença de um efeito moderado (coeficiente padronizado de 0,267) e significativo ( $p$-value $<0,001)$ para este relacionamento.

Comparando estes resultados aos encontrados por Huettermann et al. (2020), nota-se que há indícios de uma maior influência da atitude de marca de 
eSports sobre a atitude em relação ao patrocinador $(0,267)$ entre os consumidores de eSports brasileiros do que entre a população amostral suíça do artigo original $(0,181)$. Este fato pode denotar um maior engajamento dos fãs de eSports brasileiros em relação aos suíços, o que iria de acordo com a imagem geralmente aceita sobre os fãs brasileiros em praticamente qualquer segmento de entretenimento: em geral são tidos como alguns dos mais entusiásticos e engajados. Segundo a teoria do equilíbrio de Heider (1958 apud ROGERS et al., 2020), seres humanos tendem a buscar um estado de "equilíbrio", o que os leva a se sentirem de maneira similar sobre coisas que aparentam serem relacionadas. Dessa forma, o forte engajamento e afeição do consumidor brasileiro seriam transferíveis para os patrocinadores por meio de ativações de patrocínio bemsucedidas.

Quando comparado ao efeito da atitude de marca de eSport, o efeito percepção de boa vontade mostrou-se consideravelmente mais forte $(0,633)$ e igualmente significativo ( $p$-value $<0,001$ ). Rogers et al. (2020) apontam que a percepção de boa vontade é de crítica importância para patrocinadores, visto que é justamente o que separa o patrocínio de técnicas de publicidade tradicionais, como os anúncios e propagandas. A manutenção de uma ampla percepção de boa vontade é uma das mais eficientes maneiras de evitar a criação de uma imagem de oportunismo, onde se pensa que os anúncios são benéficos somente para o anunciante (ROGERS et al., 2020). Esse tipo de imagem de marca é fatal no meio dos eSports, como exemplificado pelo caso da Mercedes-Benz citado anteriormente.

Comparando o efeito da percepção de boa vontade observado neste estudo aos resultados de Huettermann et al. (2020), vê-se que no estudo original, o efeito encontrado foi mais forte $(0,880)$. Em ambos os estudos o efeito não só se mostrou forte, como também foi o maior influenciador na atitude em relação ao patrocinador. Ainda assim, um motivo possível para a menor influência da percepção de boa vontade neste estudo pode referir-se à imagem que o brasileiro tem sobre as empresas de grande porte. Em sua história recente, o Brasil acompanhou casos notórios de corrupção corporativa e política envolvendo grandes empresas, tanto do setor privado, quanto estatal, como a Odebrecht, OGX e Petrobras. Estes casos recorrentes podem ter manifestado influência na 
percepção do brasileiro sobre as empresas, tornando-os desconfiados sobre as motivações das mesmas e dificultando o reconhecimento de boa vontade ou altruísmo.

\subsubsection{Influência da Atitude de Marca de eSports e da Atitude em Relação ao Patrocinador Na Intenção de Compra de Produto do Patrocinador}

O modelo proposto apontou dois efeitos que agem diretamente sobre a intenção de compra de produto do patrocinador, o exercido diretamente pela atitude de marca de eSports (Hipótese 2b) e o exercido pela atitude em relação ao patrocinador (Hipótese 4).

Não foi verificado o efeito direto entre a atitude de marca de eSports e a intenção de compra de produto do patrocinador determinado pela hipótese $2 b$ (coeficiente padronizado $0,041, p$-value $=0,527)$. Isso contrasta tanto com o resultado de Huettermann et al. (2020), que encontraram um efeito razoável $(0,529)$, quanto com os resultados encontrados em estudos anteriores, que encontraram um efeito significante, porém de força muito baixa (BISCAIA et al., 2013; DEES et al., 2008). Dessa forma, neste estudo, conclui-se que a atitude de marca de eSports exerce influência sobre a intenção de compra de produtos do patrocinador exclusivamente de forma indireta, por meio de seu efeito sobre a atitude em relação ao patrocinador.

Por fim, a hipótese 4 foi verificada, visto que quanto mais positiva foi a atitude em relação ao patrocinador, maior foi a intenção de compra de produtos dele. Este resultado apoia o modelo de Biscaia et al. (2017) e os achados de Huettermann et al. (2020) e Dees et al. (2008). Este foi o efeito mais forte observado no modelo $(0,733)$, explicando $55,6 \%$ da variância na intenção final de compra e, comparado aos resultados de Huettermann et al. (2020) $(0,544)$ e Dees et al. (2008) (0.247), parece ser o maior coeficiente verificado na literatura para este relacionamento até o momento.

Este resultado indica que existe, no público brasileiro de eSports, uma maior relação entre a atitude em relação ao patrocinador e a intenção de compra de produtos dele do que no público suíço (HUETTERMANN et al., 2020) e no público de esportes tradicionais (DEES et al., 2008). Como descrito por 
Huettermann et al. (2020), este cenário pode criar a expectativa de maiores retornos sobre investimentos para ativações no mercado de eSports quando comparado com o mercado de esportes tradicionais e, especificamente, ativações no mercado de eSports brasileiro. 


\section{CONCLUSÕES E RECOMENDAÇÕES}

Este capítulo apresenta um resumo do estudo realizado, passando pelas etapas do trabalho e os resultados obtidos. São também apresentadas as implicações do estudo, tanto para a teoria quanto para o meio empresarial. Por fim, são apresentadas as limitações do estudo e sugestões para pesquisas futuras.

\subsection{Resumo do estudo}

Esta pesquisa seguiu os objetivos estabelecidos por Huettermann et al. (2020), buscando investigar a relação entre as motivações de consumo do públicoalvo de eSports brasileiro e sua atitude de marca em relação aos eSports. Buscou também avaliar as percepções do consumidor de eSports brasileiro sobre patrocinadores não endêmicos e determinar a efetividade dos patrocínios nos eSports.

Para este fim, foi utilizado um instrumento de pesquisa composto por traduções de escalas já existentes, desenvolvidas e testadas em pesquisas anteriores (TRAIL; JAMES, 2001; DEES et al., 2008) para realizar um crosssectional survey com uma amostra de 202 questionários válidos, composta por consumidores regulares de eSports brasileiros. Com o modelo de mensuração ajustado para os dados, foi comprovada a confiabilidade e a validade dos construtos, que foram medidos de acordo com as escalas utilizadas, apresentando tanto resultados condizentes com a literatura prévia quanto resultados divergentes.

As hipóteses da pesquisa (tabela 4.5) foram verificadas usando modelagem de equações estruturais (HAIR et al., 2009). O modelo apresentou índices de ajuste adequados e confirmou quatro das cinco hipóteses propostas, em que os efeitos mais relevantes foram: a percepção de boa vontade sobre a atitude em relação ao patrocinador e o efeito desta sobre a intenção de compra de produtos do patrocinador. Esta afirmação também se aplica aos estudos realizados por Huettermann et al. (2020) e Dees et al. (2008), indicando que esta série de efeitos se mantém a mais relevante para a predição da intenção de compra de produtos do patrocinador entre as amostras estudadas 


\subsection{Conclusões e Implicações}

Os resultados verificados nesta pesquisa representam contribuições relevantes para as teorias de marketing esportivo quando aplicadas ao contexto do emergente mercado de eSports. A maior contribuição deste estudo é na aplicação do modelo ao público consumidor de eSports brasileiro, um dos maiores no mundo emergente, buscando avaliar se a diferença em contexto socioeconômico e cultural traria diferenças nas percepções do público sobre patrocinadores.

Este trabalho corrobora o modelo proposto por Huettermann et al. (2020), adaptado do modelo teórico de Biscaia et al. (2017), confirmando a importância dos construtos de atitude de marca e percepção de boa vontade como preditores da atitude em relação ao consumidor e, por meio desta, da intenção de compra de produtos do patrocinador.

A principal diferença entre os resultados encontrados nesta pesquisa e os obtidos na literatura prévia está no fato de não ter sido verificado um efeito direto da atitude de marca de eSports na intenção de compra de produtos do patrocinador (Hipótese 2b). Este fato sugere que o público consumidor de eSports brasileiro não compra produtos de uma empresa simplesmente por ela estar presente no cenário como patrocinadora. É necessário que primeiro se desenvolva uma atitude favorável em relação ao patrocinador, tanto por meio da influência da atitude de marca de eSports, quanto por meio da percepção de boa vontade, para então notarse um aumento da intenção de compra. Isso sugere que a atitude de marca de eSports atua só indiretamente sobre a intenção de compra de produtos do patrocinador.

Em contraste aos resultados de Huettermann et al. (2020), no contexto brasileiro, a atitude de marca de eSports parece exercer uma influência maior em relação à atitude em relação ao patrocinador. A atitude em relação ao patrocinador também apresentou efeitos mais fortes que no estudo original, tendo sido aqui determinada como o fator mais influente sobre a intenção de compras de produtos do patrocinador.

Este estudo oferece insights sobre as motivações e percepções do público consumidor de eSports, tópico ainda pouco explorado na academia, em especial 
no que diz respeito ao público brasileiro. Com os resultados aqui obtidos, empresas interessadas em entrar neste mercado emergente poderão adquirir maior conhecimento quanto às peculiaridades intrínsecas ao meio, assim como munir-se de mais informações sobre as expectativas do público assíduo dos eSports, de forma a construir estratégias de patrocínio mais robustas e eficientes.

\subsection{Implicações gerenciais}

De acordo com os resultados observados por este estudo, pode-se concluir que, por meio do patrocínio de eSports no Brasil, as marcas podem conquistar melhorias em sua imagem e reconhecimento de marca, resultantes de uma melhora na atitude do público-alvo em sua relação. Podem também obter ganhos objetivos em seus resultados financeiros, visto que, conforme os resultados deste estudo, uma atitude de marca mais positiva influencia diretamente na intenção de compra do público-alvo. Esse tipo de estratégia se torna ainda mais atrativo quando se leva em consideração a documentada dificuldade de se atingir o público consumidor de eSports por vias convencionais de anúncio.

Conforme mencionado por Huettermann et al. (2020), é importante que patrocinadores reconheçam a possibilidade de construção de campanhas de ativação que conectem diretamente sua marca com motivações específicas do público-alvo. Um exemplo é a campanha de ativação com o "\#MomentsthatDeliver" da DHL, uma companhia de logística internacional, patrocinadora da ESL One. Nesta, a patrocinadora conseguiu alinhar sua marca ao drama (construto que mede atitude de marca de eSports indiretamente) associado a momentos pivotais nas partidas de eSports (HAYWARD, 2019).

Entretanto, deve-se lembrar de que as ativações de patrocínio devem ser realizadas com cuidado, focando na construção de uma imagem genuína de investimento e preocupação com os eSports, de modo que o público-alvo perceba boas intenções para com o desenvolvimento do cenário. Sendo sinceros e transparentes sobre seus esforços para agregar aos times, eventos e jogadores, pode-se cultivar uma imagem de boa vontade que, no fim, será efetiva no desenvolvimento de atitudes positivas em relação ao patrocinador. Exemplos 
como o caso da Mercedes-Benz mostram o quanto entradas percebidas como oportunistas e mal executadas podem danificar a imagem da marca ao incitar a hostilidade dos fãs de eSports.

\subsection{Limitações}

Existem algumas limitações importantes a serem consideradas no que se refere ao questionário formulado por Huettermann et al. (2020) e adaptado para o público brasileiro nesta pesquisa.

Primeiramente, as questões presentes no instrumento de pesquisa em nenhum momento relembram a distinção entre patrocinadores endêmicos de não endêmicos. No estudo original e neste, os respondentes foram informados no início do questionário de que o estudo tratava especificamente de patrocinadores não endêmicos, mas não havia nenhuma menção posterior a esse fato. Sem essa especificação durante o questionário para um público leigo em conceitos de marketing, não é possível avaliar precisamente as diferenças de percepção entre patrocinadores endêmicos e não endêmicos. Assim, os resultados obtidos deveriam ser generalizados para patrocínios no contexto de eSports em geral, não somente para patrocinadores não endêmicos.

Outra limitação referente ao formulário é o fato deste não levar em consideração quais eSports os respondentes acompanham efetivamente. É de se esperar que eSports de gêneros distintos (MOBAs, atiradores, esportes, estratégia) tenham públicos distintos, com motivações distintas. Ao emitir essa especificidade da análise, cria-se uma imagem generalizada sobre o público consumidor de eSports, o que pode gerar inconsistências quando relacionadas aos públicos de eSports distintos.

A limitação final referente ao instrumento de pesquisa é a omissão de maior detalhamento nos dados demográficos. Informações como a sexualidade dos respondentes poderiam ter auxiliado na formulação de hipóteses sobre os motivos pelos quais os resultados obtidos neste estudo se diferenciaram dos demais em alguns pontos. 
Como mencionado anteriormente, outra limitação importante foi a indisponibilidade de algumas vias de acesso ao público-alvo. A indisponibilidade de eventos físicos de eSports devido à pandemia do COVID-19, assim como o bloqueio de divulgações de links externos em plataformas como Facebook, Instagram e Twitch.tv dificultaram o acesso ao público-alvo, o que pode ter tido um efeito sobre o tamanho e qualidade da amostra.

\subsection{Sugestões para pesquisas futuras}

Dadas as limitações aqui apresentadas, pesquisas futuras devem buscar corrigir alguns dos pontos cegos apresentados pelo modelo de Huettermann et al. (2020). Primeiramente, é importante que futuramente sejam realizados estudos que façam uma distinção mais clara entre as percepções sobre patrocinadores endêmicos e não endêmicos. Autores como Rogers et al. (2020) já realizaram estudos com o intuito de analisar as diferenças nas reações do público consumidor de eSports para com patrocinadores endêmicos e não endêmicos. Ainda assim, seria importante que o instrumento de pesquisa fosse adaptado para avaliar se a diferenciação do tipo de patrocínio surtiria efeitos diferentes dos observados.

Estudos futuros poderiam também buscar diferenças de percepção sobre os patrocinadores entre diferentes categorias de eSports. Como mencionado no tópico 5.4, há uma grande variedade de eSports presentes no mercado atualmente, com públicos que podem apresentar peculiaridades em suas motivações e percepções. Já foi identificado que, no contexto dos esportes tradicionais, os públicos de esportes diferentes têm diferentes motivações para consumi-los. Um exemplo disso é o fato de que os fãs de esportes estilísticos como patinação artística e ginástica olímpica são altamente motivados pelo construto estética (XIAO, 2019), presente na EMCE (TRAIL; JAMES, 2001), se diferenciando de outros esportes. Efeitos similares podem existir nos públicos de eSports diversos.

Por fim, estudos futuros devem buscar o acesso ao público-alvo em eventos de eSports. Como mencionado anteriormente, as principais vias digitais de acesso gratuito aos consumidores de eSports (Instagram, Facebook, Twitch.tv) não permitem a divulgação de links externos para usuários comuns. Divulgando 
pesquisas fisicamente em eventos de eSports, não só seria possível acessar a população-alvo do estudo diretamente, como seria possível determinar facilmente os comportamentos e opiniões de consumidores de eSports distintos, uma vez que eventos de eSports geralmente são, em sua maioria, campeonatos de eSports específicos. 


\section{REFERÊNCIAS BIBLIOGRÁFICAS}

AAKER, D. A.; KUMAR, V. e DAY, G. S. Marketing Research. Wiley, 9 ed., 2006.

ABC DA COMUNICAÇÃO. Gillette lança promoção exclusiva para o universo de LOL e apresenta novo filme com Kami. Janeiro de 2020. Disponível em: https://www.abcdacomunicacao.com.br/gillette-lanca-promocao-exclusiva-para-ouniverso-de-lol-e-apresenta-novo-filme-com-kami/. Acesso em: 1 nov. 2021.

AGÊNCIA BRASIL. Mercado de games no Brasil deve crescer 5,3\% até 2022, diz estudo. Exame, São Paulo, 3 de agosto 2019. Disponível em: https://exame.com/negocios/mercado-de-games-no-brasil-deve-crescer-53-ate-2022-dizestudo/. Acesso em: 8 nov. 2021.

ANDERSON, J. C.; GERBING, D.W. Structural equation modeling in practice: A review and recommended two-step approach. Psychological Bulletin, v. 103, pp. 41123, 1988.

AYLES, J. Global Esports Revenue Reaches More Than \$1 Billion As Audience Figures Exceed 433 Million. Forbes Magazine, Nova Iorque, 3 dez. 2019. Disponível em: https://www.forbes.com/sites/jamesayles/2019/12/03/global-esports-revenue-reachesmore-than-1-billion-as-audience-figures-exceed-433-million/\#592d21281329. Acesso em: 8 nov. 2021.

BISCAIA, R.; CORREIA, A.; ROSADO, A. F.; ROSS, S. D.; MAROCO, J. Sport sponsorship: The relationship between team loyalty, sponsorship awareness, attitude toward the sponsor, and purchase intentions. Journal of Sport Management, v. 27(4), p. 288-302, 2013.

BISCAIA, R.; TRAIL, G.; ROSS, S.; YOSHIDA, M. A model bridging team brand experience and sponsorship brand experience. International Journal of Sports Marketing and Sponsorship, v. 18, iss 4, p. 380-399, 2017. Disponível em: https://doi.org/10.1108/IJSMS-07-2016-0038. Acesso em: 1 nov. 2021.

BYRNE, B. M. Structural Equation Modeling with AMOS: Basic Concepts, Applications and Programming. 2nd ed. Routledge, NY, 2010.

CHIMINAZZO, G; MARQUES, V. E-sports não é (mais) brincadeira. Isto é Dinheiro. Rio de Janeiro, 2020. Disponível em: https://www.istoedinheiro.com.br/e-sports-nao-emais-brincadeira/. Acesso em: 8 nov. 2021.

CHURCHILl, G. A. A Paradigm for Developing Better Measures of Marketing Constructs. Journal of Marketing, v. 16, pp. 64-73, 1979

COLMAN, A. M. A Dictionary of Psychology. Oxford: Oxford University Press, 2009.

DECI, E. L.; RYAN, R. M. The "what" and "why" of goal pursuits: Human needs and the self-determination of behavior. Psychological Inquiry, v. 11(4), p. 227-268, 2000. Disponível em: https://doi.org/10.1207/S15327965PLI1104_01Acesso em 1 nov. 2021. 
DEES, W.; BENNETT, G.; VILLEGAS, J. Measuring the effectiveness of sponsorship of an elite intercollegiate football program. Sport Marketing Quarterly, v. 17(2), p. 79$89,2008$.

ELASRI-EJJABERI，A.; RODRIGUEZ-RODRIGUEZ, S.; APARICIO-CHUECA，P. Effect of eSport sponsorship on brands: an empirical study applied to youth. Journal of Physical Education and Sport, v.20, art 122, p. 852-861, 2020. Disponível em: https://doi.org/10.7752/jpes.2020.02122. Acesso em: 8 nov. 2021.

ESL GAMING. ESL and Mountain Dew ${ }^{\circledR}$ team up for third year of Mountain Dew League after tremendous growth. ESL Gaming Network, 2018. Disponível em: https://www.eslgaming.com/press/esl-and-mountain-dew-team-third-year-mountain-dewleague-after-tremendous-growth. Acesso em 1 nov. 2021.

FENLON, W. Everything that's happened since the Activision Blizzard lawsuit went public. Nova Iorque: PC Gamer, 2021. Disponível em: https://www.pcgamer.com/activision-blizzard-lawsuit-controversy-timeline-explained/.

Acesso em: 1 nov. 2021.

FERREIRA, J. B. Aceitação e Prontidão do Consumidor para Produtos de Alta Tecnologia: Elaboração e Teste Empírico do Modelo CART para adoção de produtos de alta tecnologia. Tese de Doutorado em Ciência da Administração. Rio de Janeiro: UFRJ/COPPEAD, 2010.

FERnANDES, A. Activação De Patrocínios Desportivos. Tese de Mestrado. Lisboa: ISCTE Business School - Instituto Universitário de Lisboa, 2009.

FISHBEIN, M.; AJZEN, I. Belief, attitude, intention and behavior: An introduction to theory and research. Addison-Wesley Publishing Co, 1975.

FINK, J. S.; TRAIL, G. T.; ANDERSON, D. F. An examination of team identification: Which motives are most salient to its existence? International Sports Journal, v. 6(2), p. 195-207, 2002.

FORNELL, C.; LARCKER, D. F. Evaluating Structural Equation Models with Unobservable Variables and Measurement. Journal of Marketing Research, v. 18, pp. 39-50, 1981.

FREITAS, B. D. A.; CONTRERAS-ESPINOSA, R. S.; CORREIA, P. A. P. Identifying the pros, cons and tactics of eSports sponsorships: An integrative literature review. Comunicação Pública, v.15, n. 28, 2020. Disponível em: http://journals.openedition.org/cp/7243. Acesso em: 9 nov. 2021.

GANTZ, W.; WENNER, L. A. Fanship and the Television Sport Viewing Experience. Sociology of Sport Journal, v. 12, n. 1, p. 56-74, 1995. Disponível em:https://search.ebscohost.com/login.aspx?direct=true\&db=sih\&AN=13469857\&lang= pt-br\&site=ehost-live Acesso em: 2 nov. 2021.

GARVER, M. S.; MENTZER, J. T. Logistics Research Methods: Employing Structural Equation Modeling to Test for Construct Validity. Journal of Business Logistics, v. 20, n. 1, pp. 33-57, 1999.76

GAWRYSIAK, J.; BURTON, R.; JENNY, S.; WILLIAMS, D. Using Esports Efficiently to Enhance and Extend Brand Perceptions - A Literature Review. 
Physical culture and sport studies and research, v. 86, n. 1, p. 1-14, 2020. Disponível em: https://doi.org/10.2478/pcssr-2020-0008. Acesso em: 9 de nov. 2021.

HAIR, J. F.; BLACK, W. C.; BABIN, B. J.; ANDERSON, R. E. Multivariate Data Analysis. Upper Saddle River: Prentice-Hall, ed. 7, 2009.

HALLMANN, K.; GIEL, T. eSports - Competitive sports or recreational activity? Sport Management Review, v. 21(1), p. 14-20, 2017. Disponível em: https://doi.org/10.1016/j.smr.2017.07.011. Acesso em: 1 nov. 2021.

HAMARI, J.; SJÖBLOM, M. What is eSports and why do people watch it?. Internet Research, v. 27, p. 211-232, 2017. Disponível em: https://doi.org/10.1108/IntR-04-20160085. Acesso em: 1 nov. 2021.

HAYWARD, A. Cars, drinks, and clothes: Non-endemic sponsor recap for Q1 2019. The Esports Observer, 2019. Disponível em: https://esportsobserver.com/non-endemicsponsors-q12019/. Acesso em: 06 nov. de 2021.

HERSHEY, W. Investing in esports teams. Roundhill Investments, 2020. Disponível em: https://www.roundhillinvestments.com/research/investing/investing-in-esports-teams. Acesso em: 8 nov. 2021.

HITT, K. BMW goes global with sports, signs five major esports teams. The Esports Observer, 2020. Disponível em: https://esportsobserver.com/bmw-global-partnersesports-teams/. Acesso em: 1 nov. 2021.

HUETTERMANN, M.; TRAIL, G.; PIZZO, A. D.; STALlONE, V. Esports Sponsorship: An Empirical Examination of Esports Consumers Perceptions of NonEndemic Sponsors. Journal of Global Sport Management, 2020. Disponível em: https://doi.org/10.1080/24704067.2020.1846906. Acesso em: 1 nov. 2021.

HU, L.; BENTLER, P. M. Cutoff criteria for fit indexes in covariance structure analysis: Conventional criteria versus new alternatives. Structural Equation Modeling, v. 6, pp. 1-55, 1999.

JAMES, J. D.; KOLBE, R. H.; TRAIL, G. T. Psychological attachment to a new sports team: Building or maintaining the consumer base. Sport Marketing Quarterly, v. 11, n. 4, p. 215-225, 2002.

LEE, D.; TRAIL, G. T.; ANDERSON, D. F. Motives and identification of hockey spectators: Relevance to marketing ACHA hockey. International Journal of Sport Management and Marketing, v. 5(1/2), p. 132-150, 2009. Disponível em: https://doi.org/10.1504/IJSMM.2009.021755. Acesso em: 1 nov. 2021.

MADRIGAL, R. Social identity effects in a belief-attitude-intentions hierarchy: Implications for corporate sponsorship. Psychology\& Marketing, v. 18(2), p. 145-165, 2001.

MALHOTRA, N. K. Pesquisa de marketing, uma orientação aplicada. Porto Alegre: Bookman, ed. 4, 2006.

MAZODIER, M.; QUESTER, P. The role of sponsorship fit for changing brand affect: A latent growth modeling approach. International Journal of Research in Marketing, v.31(1), p. 16-29, 2014. Disponível em: https://doi.org/10.1016/j.ijresmar.2013.08.004. Acesso em: 9 nov. 2021. 
MEENAGHAN, T. "Commercial sponsorship”. European Journal of Marketing, v. 7, p. $5-71,1983$.

NEWZOO. 2021 Global Games Market Report: The VR \& Metaverse Edition. Amsterdam, 2021. Disponível em: https://newzoo.com/insights/trend-reports/newzooglobal-games-market-report-2021-free-version/. Acesso em: 8 nov. 2021.

NICKELL, D.; CORNWELL, T. B.; JOHNSTON, W. J. Sponsorship-linked marketing: a set of research propositions. Journal of Business \& Industrial Marketing, 26(8), 577-589, 2011.

NIELSEN SPORTS. Esports playbook for brands. Nielsen, 2019. Disponível em: https://nielsensports.com/esports-playbook-for-brands/. Acesso em: 8 nov. 2021.

NUNNALly, J.; BERNSTEIN, I. Psychometric Theory. McGraw-Hill Humanities/Social Sciences/Languages, ed. 3, 1994.

PARASURAMAN, A.; GREWAL, D. e KRISHNAN, R. Marketing Research. SouthWestern College Pub, ed. 2, 2006.

PERCEY, L.; ROSSITER, J. R. A model of brand awareness and brand attitude advertising strategies. Psychology\& Marketing. v. 9(4), p. 263-274, 1992.

PIZZO, A. D.; BAKER, B. J.; NA, S.; LEE, M.; KIM, K.; FUNK, D. C. eSport vs. sport: A comparison of spectator motives. Sport Marketing Quarterly, v. 27(2), p. 4560, 2018.

QIAN, T. Y.; WANG, J. J.; ZHANG, J. J.; LU, L. Z. It is in the game: Dimensions of sports online spectator motivation and development of a scale. European Sport Management Quarterly, v. 20, n. 4, p. 458-479, 2020. Disponível em: https://doi.org/10.1080/16184742.2019.1630464. Acesso em: 9 de nov. 2021.

RED BULL. Red Bull M.E.O. International Online Qualifiers. Red Bull, 2021. Disponível em: https://www.redbull.com/sg-en/events/red-bull-meo-international-onlinequalifiers. Acesso em: 1 nov. 2021.

REIS, G. CBLoL 2021: a história dos times selecionados no sistema de franquias. Globo Esporte, $2020 . \quad$ Disponível em: https://globoesporte.globo.com/esports/lol/noticia/cblol-2021-times-do-sistema-defranquias-a-historia-de-cada-um.ghtml. Acesso em 8 nov. 2021.

ROBINSON, M.; TRAIL, G. T. Relationships among spectator gender, motives, points of attachment, and sport preference. Journal of Sport Management, v. 19(1), p. 58-80, 2005. Disponível em: https://doi.org/10.1123/jsm.19.1.58. Acesso em: 1 nov. 2021.

ROGERS, R.; FARQUHAR, L.; MUMMERT, J. Audience response to endemic and non-endemic sponsors of esports events. International Journal of Sports Marketing and Sponsorship, v.21, n. 3, p. 561-576, 2020. Disponível em: https://www.emerald.com/insight/1464-6668.htm. Acesso em: 1 nov. 2021.

SHABIR, N. ESports: The Complete Guide 17/18: A guide for gamers, teams, organizations and Other entities in, or looking to get into the space. Wroclaw: Publicação independente, 2017. 
SCHREIBER, J. B.; STAGE, F. K.; KING, J.; NORA, A. e BARLOW, E. A. Reporting Structural Equation Modeling and Confirmatory Factor Analysis Results: A Review. Journal of Educational Research, v. 99, n. 6, pp. 323-337, 2006.

SPERBER, A. D. Translation and validation of study instrument for cross-cultural research. Gastroenterology, v. 126, n. 1, pp 124-128, 2004.

STRÖH, J. H. A. The Esports Market and Esports Sponsoring. Marburg: TectumVerlag, 2017.

TRAIL, G. T.; ANDERSON, D. F.; FINK, J. S. A theoretical model of sport spectator consumption behavior. International Journal of Sport Management, v.1(3), p. 154-180, 2000 .

TRAIL, G. T.; JAMES, J. D. The motivation scale for sport consumption: Assessment of the scale psychometric properties. Journal of Sport Behavior, v. 24(1), p. 108-127, 2001.

WEISS, T.; SCHIELE, S. Virtual worlds in competitive contexts: Analyzing eSports consumer needs. Electronic Markets, v. 23, p. 307-316, 2013. Disponível em: https://doi.org/10.1007/s12525-013-0127-5. Acesso em: 1 nov. 2021.

XIAO, M. Factors Influencing eSports Viewership: An Approach Based on the Theory of Reasoned Action. Communication \& Sport. v.8(1), p. 92-122, 2019. Disponível em: https://doi.org/10.1177/2167479518819482. Acesso em: 9 nov. 2021 


\section{APÊNDICES}

Apêndice A - Questionário utilizado na pesquisa

\section{INTRODUÇÃO}

Prezado(a) entrevistado(a),

O questionário abaixo se refere a um trabalho de pesquisa acadêmica desenvolvida para o IAG, escola de negócios da PUC-Rio.

O tema a ser abordado é a percepção do consumidor brasileiro de eSports sobre os patrocinadores do setor.

eSports são aqui definidos como jogos eletrônicos competitivos e seus campeonatos.

Exemplos são: League of Legends e o CBLOL, o Counter Strike e o Free Fire com a Liga Brasileira de Free Fire.

As respostas para este questionário são anônimas.

Muito obrigado por sua participação.

\section{VALIDAÇÃO}

V1 Você assiste eSports?

o Sim

o Não

V2 Com que frequência você assiste eSports?

o Muito frequentemente

o Frequentemente

o Ocasionalmente

o Raramente

o Nunca

\section{DEMOGRAFIA}

D1 Qual é a sua idade?

o Abaixo de 18

o $\quad 18$ a 24

o 25 a 34

o 35 a 44

o 45 a 54

o 55 ou mais

D2 Qual é o seu gênero?

o Masculino

o Feminino 
o Não binário/terceiro gênero

o Prefere não dizer

D3 Qual é sua faixa de renda?

o Menos de dois salários-mínimos

o De dois a três salários-mínimos

o De três a quatro salários-mínimos

o De quatro a cinco salários-mínimos

o Acima de cinco salários-mínimos

D4 Qual é o seu grau de escolaridade?

o Ensino fundamental incompleto

o Ensino fundamental completo

o Ensino médio incompleto

o Ensino médio completo

o Ensino superior incompleto

o Ensino superior completo

o Pós-graduado

D5 Qual é sua ocupação?

o Empregado em tempo integral

o Empregado em meio período

o Dono(a) de casa

o Estudante

o Desempregado

o Outro

\section{ESCALA DE MOTIVAÇÃO PARA CONSUMO DE ESPORTS (EMCE)}

4.1 Conquista Vicária (CV)

CV1 Assistir eSports aumenta minha autoestima.

o Concordo totalmente

o Concordo

o Não concordo nem discordo

o Discordo

o Discordo totalmente

CV2 Assistir eSports faz com que eu me sinta valorizado.

o Concordo totalmente

o Concordo

o Não concordo nem discordo

o Discordo

o Discordo totalmente

CV3 Assistir eSports faz com que eu me respeite mais.

o Concordo totalmente

o Concordo

o Não concordo nem discordo

o Discordo

o Discordo totalmente

4.2 Estética (EST)

EST1 Eu aprecio o valor artístico dos eSports. 

o Concordo totalmente
o Concordo
o Não concordo nem discordo
o Discordo
o Discordo totalmente

EST2 Eu gosto da beleza e elegância dos eSports.
o Concordo totalmente
o Concordo
o Não concordo nem discordo
o Discordo
o Discordo totalmente

EST3 eSports são uma forma de arte.

o Concordo totalmente

o Concordo

o Não concordo nem discordo

o Discordo

o Discordo totalmente

\subsection{Drama (DR)}

DR1 Eu prefiro partidas de eSports disputadas do que partidas dominadas por uma equipe.

o Concordo totalmente

o Concordo

o Não concordo nem discordo

o Discordo

o Discordo totalmente

DR2 Eu gosto de partidas de eSports em que o resultado é incerto.

o Concordo totalmente

o Concordo

o Não concordo nem discordo

o Discordo

o Discordo totalmente

DR3 Em eSports, uma partida disputada é mais gratificante que uma partida dominada por um único time.

o Concordo totalmente

o Concordo

o Não concordo nem discordo

o Discordo

o Discordo totalmente 


\subsection{Escapismo (ESC)}

ESC1 eSports me dão a oportunidade momentânea de escapar da realidade de meu cotidiano.

o Concordo totalmente

o Concordo

o Não concordo nem discordo

o Discordo

o Discordo totalmente

ESC2 Eu consigo escapar das tensões em minha vida por meio dos eSports.

o Concordo totalmente

o Concordo

o Não concordo nem discordo

o Discordo

o Discordo totalmente

ESC3 Os eSports me fornecem uma distração momentânea do meu cotidiano.

o Concordo totalmente

o Concordo

o Não concordo nem discordo

o Discordo

o Discordo totalmente

4.5 Aquisição de Conhecimento (AC)

AC1 Assistindo eSports, eu posso aumentar meu conhecimento sobre o game em questão.

o Concordo totalmente

o Concordo

o Não concordo nem discordo

o Discordo

o Discordo totalmente

AC2 Assistindo eSports, eu posso aumentar a minha compreensão sobre a estratégia do game.

o Concordo totalmente

o Concordo

o Não concordo nem discordo

o Discordo

o Discordo totalmente

AC3 Assistindo eSports, eu posso aprender sobre os aspectos técnicos envolvidos no game.

o Concordo totalmente

o Concordo

o Não concordo nem discordo

o Discordo

o Discordo totalmente 
4.6 Habilidades Físicas (HF)

HF1 Eu aprecio a habilidade dos jogadores de eSports.

o Concordo totalmente

o Concordo

o Não concordo nem discordo

o Discordo

o Discordo totalmente

HF2 Eu aprecio o desempenho dos jogadores de eSports.

o Concordo totalmente

o Concordo

o Não concordo nem discordo

o Discordo

o Discordo totalmente

HF3 Eu aprecio a coordenação motora dos jogadores de eSports.

o Concordo totalmente

o Concordo

o Não concordo nem discordo

o Discordo

o Discordo totalmente

4.7 Interação Social (IS)

IS1 Eu gosto de socializar com outras pessoas a respeito de eSports.

o Concordo totalmente

o Concordo

o Não concordo nem discordo

o Discordo

o Discordo totalmente

IS2 Eu gosto de ter a oportunidade de interagir com outras pessoas por meio dos eSports.

o Concordo totalmente

o Concordo

o Não concordo nem discordo

o Discordo

o Discordo totalmente

IS3 Eu gosto de conversar com outras pessoas por meio dos eSports.

o Concordo totalmente

o Concordo

o Não concordo nem discordo

o Discordo

o Discordo totalmente 


\subsection{Atratividade Física (AF)}

AF1 Eu gosto de assistir jogadores de eSports que são fisicamente atraentes.

o Concordo totalmente

o Concordo

o Não concordo nem discordo

o Discordo

o Discordo totalmente

AF2 O motivo principal para eu assistir eSports é que eu acho os(as) jogadores(as) fisicamente atraentes.
o Concordo totalmente
o Concordo
o Não concordo nem discordo
o Discordo
o Discordo totalmente

AF3 O "sex appeal" de um jogador específico é um grande motivo por qual eu assisto eSports.

o Concordo totalmente

o Concordo

o Não concordo nem discordo

o Discordo

o Discordo totalmente

\subsection{Agressividade (AGR)}

AGR1 Eu aprecio o conflito e o jogo duro que ocorre em partidas de eSports.

o Concordo totalmente

o Concordo

o Não concordo nem discordo

o Discordo

o Discordo totalmente

AGR2 Eu aprecio a atmosfera de competitividade agressiva nas partidas de eSports.

o Concordo totalmente

o Concordo

o Não concordo nem discordo

o Discordo

o Discordo totalmente

AGR3 Eu aprecio o comportamento agressivo dos jogadores de eSports durante as partidas.
o Concordo totalmente
o Concordo
o Não concordo nem discordo
o Discordo
o Discordo totalmente 
AGR4 Eu aprecio a hostilidade e intimidação que faz parte de partidas de eSports.

o Concordo totalmente

o Concordo

o Não concordo nem discordo

o Discordo

o Discordo totalmente

4.10 Novidade (NOV)

NOV1 Eu aprecio o surgimento de uma nova equipe de eSports.

o Concordo totalmente

o Concordo

o Não concordo nem discordo

o Discordo

o Discordo totalmente

NOV2 Eu gosto de ter a oportunidade de assistir uma nova equipe de eSports.

o Concordo totalmente

o Concordo

o Não concordo nem discordo

o Discordo

o Discordo totalmente

NOV3 A oportunidade de assistir partidas de uma nova equipe de eSports é divertida.

o Concordo totalmente

o Concordo

o Não concordo nem discordo

o Discordo

o Discordo totalmente

\section{ESCALA DE ATITUDE DE MARCA DE ESPORTS (AME)}

AME1 É importante para mim ser uma parte dos eSports.

o Concordo totalmente

o Concordo

o Não concordo nem discordo

o Discordo

o Discordo totalmente

AME2 Meus amigos me consideram um grande fã de eSports.

o Concordo totalmente

o Concordo

o Não concordo nem discordo

o Discordo

o Discordo totalmente

AME3 É muito importante para mim que games de eSports sejam jogados.

o Concordo totalmente

o Concordo

o Não concordo nem discordo

o Discordo

o Discordo totalmente 
AME4 Eu me vejo como um grande fã de eSports.

o Concordo totalmente

o Concordo

o Não concordo nem discordo

o Discordo

o Discordo totalmente

\section{ESCALA DE PERCEPÇÃO DE BOA VONTADE (PBV)}

PBV1 Patrocinadores de eSports estão envolvidos com a sociedade.

o Concordo totalmente

o Concordo

o Não concordo nem discordo

o Discordo

o Discordo totalmente

PBV2 Os patrocinadores estão tentando melhorar os eSports.

o Concordo totalmente

o Concordo

o Não concordo nem discordo

o Discordo

o Discordo totalmente

PBV3 Os patrocinadores cuidam dos fãs de eSports.

o Concordo totalmente

o Concordo

o Não concordo nem discordo

o Discordo

o Discordo totalmente

\section{ESCALA DE ATITUDE EM RELAÇÃO AO PATROCINADOR (ARP)}

ARP1 Eu tenho um olhar positivo sobre empresas que patrocinam eSports.

o Concordo totalmente

o Concordo

o Não concordo nem discordo

o Discordo

o Discordo totalmente

ARP2 Empresas que promovem os eSports são bem-sucedidas.

o Concordo totalmente

o Concordo

o Não concordo nem discordo

o Discordo

o Discordo totalmente

ARP3 Empresas que apoiam os eSports oferecem produtos/serviços de alta qualidade.
o Concordo totalmente
o Concordo
o Não concordo nem discordo
o Discordo
o Discordo totalmente 
ARP4 Empresas que patrocinam eSports são profissionais.

o Concordo totalmente

o Concordo

o Não concordo nem discordo

o Discordo

o Discordo totalmente

\section{ESCALA DE INTENÇÃO DE COMPRA DE PRODUTO DO PATROCINADOR} (ICPP)

ICPP1 Eu consideraria comprar produtos/serviços de patrocinadores de eSports.

o Concordo totalmente

o Concordo

o Não concordo nem discordo

o Discordo

o Discordo totalmente

ICPP2 Eu experimentaria um produto/serviço de um patrocinador se eu o visse no ambiente dos eSports.

o Concordo totalmente

o Concordo

o Não concordo nem discordo

o Discordo

o Discordo totalmente

ICPP3 Eu definitivamente compraria produtos/serviços de patrocinadores de eSports.

o Concordo totalmente

o Concordo

o Não concordo nem discordo

o Discordo

o Discordo totalmente

ICPP4 Em geral, minha atitude em relação a comprar produtos/serviços de empresas que patrocinam eSports é positiva.

o Concordo totalmente

o Concordo

o Não concordo nem discordo

o Discordo

o Discordo totalmente 